\title{
Are small investors naive about incentives?
}

\author{
Ulrike Malmendier $^{\mathrm{a}^{*}}$, Devin Shanthikumar ${ }^{\mathrm{b}}$ \\ ${ }^{a}$ University of California, Department of Economics, 549 Evans Hall, \#3880, \\ Berkeley, CA, 94720-3880, USA \\ ${ }^{b}$ Harvard Business School, Soldiers Field Road, Morgan Hall 377, \\ Boston, MA, 02163, USA
}

Journal of Financial Economics, August 2007, vol. 85 (2), pp. 457-489.

\section{Abstract}

Security analysts tend to bias stock recommendations upward, particularly if they are affiliated with the underwriter. We analyze how investors account for such distortions. Using the NYSE Trades and Quotations database, we find that large traders adjust their trading response downward: they exert buy pressure following strong buy recommendations, no reaction to buy recommendations, and selling pressure following hold recommendations. This "discounting" is even more pronounced when the analyst has an underwriter affiliation. Small traders, instead, follow recommendations literally. They exert positive pressure following both buy and strong buy recommendations and zero pressure following hold recommendations. We discuss possible explanations for the differences in trading response, including information costs and investor naiveté.

JEL Classifications: G14, G25, G29, D82, D83.

Keywords: Stock recommendations; Trade reaction; Individual and institutional investors; Conflicts of interest; Behavioral finance

We would like to thank Nick Barberis, Stefano DellaVigna, Ming Huang, Ilan Kremer, Charles Lee, Roni Michaely, Marco Ottaviani, Oguz Ozbas, Josh Pollet, Paul Schultz, René Stulz, Adam Szeidl, Richard Thaler, Kent Womack, an anonymous referee, and seminar participants at Harvard, London Business School, Northwestern University, Stanford, Università Bocconi (IGIER), University of Florida, University of Illinois at Urbana-Champaign, University of Madison-Wisconsin, USC, UT Austin, University of Utah, and Washington University in St. Louis as well as the SITE (Economics \& Psychology) 2003, NBER Behavioral Finance Fall 2003, WFA 2004, N.Y.Fed/Ohio State University/JFE 2004, and HBS IMO 2005 conferences for very helpful comments. Michael Jung provided excellent research assistance.

*Corresponding author contact information: ulrike@econ.berkeley.edu 


\section{Introduction}

Stock recommendations of security analysts exhibit a strong upward bias. While the scale of recommendations ranges from "strong sell" and "sell" to "hold," "buy," and "strong buy," only $4.5 \%$ of all recommendations recorded in the IBES data set through December 2002 are in the strong sell and sell categories. Analysts' true scale appears to be shifted upward. The upward bias is even more pronounced for analysts who are affiliated with the underwriter of the recommended stock.

In this paper, we document the trade reaction of investors to recommendations. Using the NYSE Trades and Quotations database, we investigate how large and small traders respond to recommendations issued by affiliated and unaffiliated analysts.

We find three main results. First, both large and small traders display significant trade reactions. But only large traders adjust their trading response to the upward distortion. They exhibit a positive abnormal trade reaction to strong buy recommendations, no reaction to buy recommendations, and significant selling pressure after holds. Small traders, by contrast, follow recommendations literally. They exhibit a positive abnormal reaction to both buy and strong buy recommendations and no reaction to holds. Second, large traders react significantly less positively to buy and strong buy recommendations if the analyst is affiliated (their overall reaction is insignificantly negative). Small traders, instead, do not respond differently to affiliated recommendations. Third, small investors appear to take less account of the informational content of a recommendation change (or the lack thereof). For example, small investors respond positively to mere reiterations of buy and strong buy (unaffiliated) recommendations, while large investors do not display any significant reaction. The results are robust to alternative econometric specifications, 
including alternative investor and analyst classifications, controls for analyst and brokerage heterogeneity, and tests for front running of large traders.

Our results reveal systematic and robust differences in how small and large investors react to analyst reports. It is harder to pin down the explanation for those differences. One possibility is that information about analyst distortions is more costly for small investors - the costs of adjusting their trading behavior outweigh the benefits. In fact, the benefits could be small or even zero due to the arbitrage of large investors. Alternatively, small investors might not seek (or internalize) information about analyst distortions even if the costs of obtaining such information are low. They take recommendations at face value and trust analysts too much, in line with experimental results on advice-giving and the literature on investors' reaction to firms' accounting choices and security issuance decisions (Schotter, 2003; Daniel, Hirshleifer, and Teoh, 2002).

To differentiate between these explanations would require estimates of the costs of and returns to information about analyst distortions. However, informational costs are hard to measure objectively. The returns are, in principle, easier to calculate, but the NYSE Trades and Quotations database does not allow such calculations since it does not reveal investors' portfolio strategies (only aggregate trade imbalances).

As a second-best approach, we analyze the relation between abnormal returns and trade imbalance. Using an event-study methodology, we find that small investors' net (buy minus sell) trade reaction predicts significantly lower abnormal returns than large investors' net trade reaction over six and twelve months. The difference is insignificant if we assume a three-month holding period. We also calculate the portfolio returns to a trading strategy that takes recommendations literally, i.e., buys after buy and strong buy recommendations and sells after sell and strong sell recommendations. Using the Fama-French four-factor portfolio method, we find mostly insignificant abnormal returns. 
Two additional results shed some light on the underlying motives of small investors. First, investors face $94.5 \%$ positive and neutral recommendations, revealing the general distortion at no (additional) cost to those who trade in response to recommendations. Thus, rational small investors should be aware of the general upward shift of recommendations by all analysts. Nevertheless, they fail to account for it. Second, while it might be costly to distinguish affiliated and unaffiliated analysts and to identify the additional distortion of affiliated analysts, small investors can minimize the cost by focusing on analysts who are most easily identified as "independent": analysts whose financial institutions are never involved in underwriting. However, we find that small investors display less abnormal trade reaction to such analyst recommendations.

Our paper builds on a large literature on the informational distortions of analysts (Francis, Hanna, and Philbrick, 1997; Lin, McNichols, and O’Brien, 2003, among many others). Several papers document that the recommendations of affiliated analysts are more favorable than those of unaffiliated analysts (see, e.g., Dugar and Nathan, 1995; Lin and McNichols, 1998; and Michaely and Womack, 1999). The high ratio of buy over sell recommendations indicates that even unaffiliated analysts do not provide a balanced view (Michaely and Womack, 2005). ${ }^{1}$

Previous analyses of investor reaction to recommendations have been largely based on return patterns. Womack (1996) finds significant three-day event returns to recommendation changes in the direction of the change. The evidence on return differences if analysts are affiliated is mixed. For initial public offering (IPO) underwriting affiliation, Michaely and Womack (1999) show that both the initial positive reaction to upgrades and the post-recommendation drift are stronger if the analyst is unaffiliated. For secondary equity offering (SEO) underwriting affiliation, Lin

\footnotetext{
${ }^{1}$ Optimism in forecasts, price targets, and long-term growth forecasts, even among unaffiliated analysts, point in the same direction. See, for example, Rajan and Servaes (1997), Dechow, Hutton, and Sloan (1999), Chan, Karceski, and Lakonishok (2002), Brav, Lehavy, and Michaely (2003), and Brav and Lehavy (2003). Malmendier and Shanthikumar (2004) suggest, however, that distortion in recommendations does not necessarily correlate with distortion in earnings forecasts.
} 
and McNichols (1998) find that the market reacts significantly more negatively to affiliated than to unaffiliated hold recommendations, but they do not find significant differences in longer run. Iskoz (2002) shows that institutions account for analyst bias, as far as one can deduce from quarterly institutional ownership data. Mikhail et al. (2006) also analyze the reaction of small and large investors to recommendations, but use dollar trading volume. Their general results are consistent with our findings, though they do not find significant results for affiliated recommendations, possibly due to the skewness of the dollar measure for large trades.

We complement the previous findings in three ways. First, we document the trading response to affiliated and unaffiliated recommendations using measures of buyer and seller initiation as in Odders-White (2000). Second, we distinguish between small and large investors, using the tradesize algorithm developed in Lee and Radhakrishna (2000). We show that large investors - a group dominated by firms and their associated professionals - account for analyst distortions, but small investors do not. Third, we investigate the costs of and returns to adjusting for analyst distortions and relate them to different explanations for the observed trade reaction.

In the remainder of the paper, we first provide details on the various data sources (Section 2), including the classification of investor types and evidence of analyst distortions. Section 3 presents our core result, documenting the trade reaction of small and large investors to analyst recommendations. In Section 4, we discuss several potential explanations and provide a partial analysis of the costs of and the returns to informed trading. Section 5 concludes.

\section{Data}

\subsection{Data sources}

We examine data on securities trading, analyst recommendations, and underwriting. The raw trading data are from the New York Stock Exchange Trades and Quotations database (TAQ), which reports every quote and round-lot trade since January 1, 1993 on NYSE, AMEX, and 
NASDAQ. We examine ordinary common shares of U.S. firms traded on NYSE. We exclude AMEX and NASDAQ data both since the Lee-Ready algorithm, used to measure trade responses, is error-prone if multiple market makers produce quotes and since the trade-size investor classification is based on NYSE data (Lee and Radhakrishna, 2000; Odders-White, 2000).

We obtain sell-side analyst recommendations and brokerage information since October 29, 1993 from IBES. IBES converts recommendations into a uniform numerical format. We reverse the original IBES coding to $5=$ strong buy, $4=$ buy, $3=$ hold, $2=$ sell, and $1=$ strong sell. Thus, an "upgrade" translates into a positive change in the numerical value.

We identify upgrades, downgrades, and reiterations relative to the previous recommendation on the same stock by the same brokerage. An initiation is the first recommendation of a brokerage for a stock or, if the brokerage had previously stopped coverage of the stock, a new recommendation. As a robustness check, we use analyst identifiers (rather than brokerage firm identifiers) to classify recommendations. Both methods are largely identical because brokerage firms generally only have one outstanding recommendation on a stock. The analyst-based method forgoes "anonymous" recommendations (with default analyst code 0 ).

In order to account for left-censoring of the data, which prevents the classification of recommendations at the beginning of our sample period, we drop the first 179 days of the IBES sample period (corresponding to the median time between recommendation updates) when splitting the sample into initiations and other types of recommendations. Any recommendation after 179 days (April 26, 1994) with no preceding recommendation for the same stock by the same brokerage is classified as an inititiation. Alternatively, we drop only those recommendations within the first 179 days that cannot be classified, giving more weight to recommendations that are updated more frequently. All results (see the lower half of Table IV) remain virtually identical. 
The IBES data contain an unusually high number of recommendations during the first three months, raising concerns about the consistency of the early data. ${ }^{2}$ To account for these reporting anomalies and also to exclude the "scandal effects" of 2001 and 2002 as well as the effects of NASD Rule 2711 on the distribution of recommendations (Barber, Lehavy, McNichols, and Trueman, 2004), we focus on the period February 1994 through July 2001, containing 2,252 securities and 2,229 firms, but we have checked the robustness of the results to using the entire IBES sample period (October 29, 1993 through December 31, 2002).

We classify analysts (or brokerages) as "affiliated" if they belong to a bank that has an underwriting relationship with the firms they are reporting on. As in previous literature (Lin and McNichols, 1998; Michaely and Womack, 1999), we require that the bank was the lead underwriter in an IPO in the past five years or an SEO in the past two years, or a co-underwriter over the same periods. We also examine two sources of underwriting bias that have not been explored previously: SEO underwriting in the next one or two years, and lead underwriting of bonds in the past year. Future underwriters might issue higher recommendations to gain business, to increase future offer prices, or due to winner's curse. For bond underwriters, positive coverage could be part of an implicit agreement with the issuer, as it is for equity issues. Our analysis focuses on the traditional affiliation measures, both to conform to previous literature and to minimize informational asymmetries between large and small investors, e.g., about future underwriting.

We obtain underwriting data for 1987-2002 from the Securities Data Corporation (SDC) New Issues database and link it to IBES brokerage firms by company name (from the IBES recom-

\footnotetext{
${ }^{2}$ While the number of recommendations per year (and per month) is fairly uniform from 2/1994-12/2001, the first two months and three days contain substantially more observations. This could reflect large layoffs in the securities industry: The number of analysts and stocks covered declines sharply, from 626 analysts and 1,166 stocks in $11 / 1993$ to 435 analysts and 591 stocks in 2/1994. However, monthly data from U.S. Dept. of Labor Statistics (DOLS) indicate that the drop in employment is not as sharp as the IBES data suggest. That may be because the DOLS data includes all employees in the securities industry, and equity analysts might have been laid off disproportionately. But it also leaves room for concerns about data consistency within the IBES sample.
} 
mendation broker identification file). We improve the match using company websites and news articles, in particular to determine subsidiary relationships and corporate name changes, and using the mapping of Kolasinski and Kothari (2004). ${ }^{3}$

We obtain security prices, returns, and shares outstanding from the Center for Research in Security Prices (CRSP), and company variables from COMPUSTAT. The merged data set extends from October 29, 1993 to December 31, 2002 (with underwriting data since 1987), and contains 173,950 recommendations with linked trading data, for 2,424 securities of 2,397 firms. Only $12 \%$ of firms lack recommendations, so that our final sample contains almost the entire set of domestic NYSE firms with common stock. We refine the return data by setting returns equal to zero in cases where CRSP codes returns as missing because they are missing on a given day or the last valid price is more than ten days old. From a holding-period perspective, the effective returns are zero in both cases.

\subsection{Investor classification}

We consider separately the trading behavior of large and small investors. Large traders are likely to be institutional investors, such as pension funds; small traders are more likely to be individual investors. While the composition of the two groups of traders is not crucial for our analysis, it suggests a number of reasons why large traders, but not small traders adjust for analyst distortions, as documented in the literature Behavioral Industrial Organization (Ellison, 2006; DellaVigna and Malmendier, 2004). First, professional investment managers spend their full working time on investment decisions. Repetition, more frequent feedback, and specialization facilitate learning about analyst incentives. Second, finance professionals have a better financial education and better investment skills than the average individual, as illustrated by the

\footnotetext{
${ }^{3}$ We are grateful to Adam Kolasinski and S.P. Kothari for providing us with their mapping, which refines the matches using corporate websites, LexisNexis, Hoover's Online, and the Directory of Corporate Affiliations.
} 
anomalous trade reaction of small traders to earnings news (see, e.g., Lee, 1992; Bhattacharya, 2001; and Shanthikumar, 2003). Finally, when individuals follow bad investment recommendations they forgo returns but will continue to manage their personal funds. Institutions, instead, lose investors and are driven out of the market. Though institutions might not invest optimally, due to misaligned incentives and managerial entrenchment (Lakonishok, Shleifer, and Vishny, 1992), they are more likely to overcome the informational distortions in recommendations.

We distinguish small and large investors by trade size. Lee and Radhakrishna (2000) propose dollar cutoffs based on the three-month Transaction Order and Quote (TORQ) sample from 1990-1991, which reveals the identity of traders and thus allows verifying the accuracy of the classification as individual or institutional investors. Lee and Radhakrishna remove medium-size trades to minimize noise. We follow their suggestion and use $\$ 20,000$ and $\$ 50,000$ cutoffs. Our results are robust to variations in cutoffs and using share-based rather than dollar-based cutoffs.

We take additional steps to examine the reliability of the trade-size classification, especially given recent changes in trade sizes documented by Kaniel, Saar, and Titman (2005). We obtain data on the portfolio size of individual investors from 1992 until 1998 from the Federal Reserve Bank's Survey of Consumer Finances and until 2002 from the Equity Ownership in America study of the Securities Industry Association and the Investment Company Institute. In each year, we find that $60-75 \%$ of the portfolios of individuals are smaller than $\$ 50,000$. Thus, individual trades above $\$ 50,000$ are unlikely. A third source, the NYSE Fact Book, documents trade sizes directly. From 1991 to 2001, the categories of small (up to 2,099 shares), medium $(2,100-4,999$ shares), and large (5,000 shares and above) trades had very stable market shares of $20 \%, 10 \%$, and $70 \%$ respectively. After 2001 , the shares of large and small trades converged to about $45 \%$ each. The stability until 2001 confirms that the Lee-Radhakrishna investor classification applies to our sample period — but changes shortly afterwards. 
As a last empirical check, we analyze a large non-public dataset of individual accounts at a large discount brokerage firm over the period 1991-1996. ${ }^{4}$ The vast majority of individual trading lies below $\$ 20,000$. The mean (median) trade size is $\$ 12,300(\$ 5,256)$ for common stock. The $90^{\text {th }}$ percentile lies below $\$ 30,000$, and even the $95^{\text {th }}$ percentile is below the $\$ 50,000$ cutoff. Thus, the data corroborates our categorization of small traders for the subset of retail investors.

We conclude that the Lee-Radhakrishna classification is likely to perform properly in the 1990s and worse thereafter. ${ }^{5}$ To test for time trends, we repeat our core analysis year by year.

\subsection{Distortions of analyst recommendations}

Sell-side analysts face a well-known conflict of interest when providing investment advice. On the one hand, reliable recommendations attract customers and enhance the analyst's reputation. On the other hand, buy recommendations are more likely to generate trading business than sell recommendations, given short-selling constraints. Moreover, management tends to complain about low ratings and to "freeze out" the issuing analysts, and buy-side clients push for positive recommendations on stocks that they hold. ${ }^{6}$ Analysts face additional pressures if their brokerage is affiliated. Favorable recommendations are generally viewed as an implicit condition of underwriting contracts (Michaely and Womack, 1999; Lin, McNichols, and O’Brien, 2003; Bradley, Jordan, and Ritter, 2003; Conrad, Cornell, Landsman, and Rountree, 2004). Directly or indirectly, analyst compensation depends on the "support" in generating corporate finance profits (Hong and Kubik, 2003; Chan et al., 2003). Sorting can enhance the distortion. Analysts might

\footnotetext{
${ }^{4}$ We thank Terry Odean and Itamar Simonson for the data.

${ }^{5}$ Increasing internalization and trade-shredding are among the reasons for the changes after the $1990 \mathrm{~s}$. See, for example, Wall Street \& Technology, "The Market Makers' Makeover - Decimal pricing and razor-thin profit margins are pushing wholesale market makers to overhaul their trading operations," 7/1/2003, and the Wall Street Journal, "SEC Urges U.S. Stock Markets To Help Stop Splitting of Trades," 1/25/2005.

${ }^{6}$ See Lin and McNichols (1998); Francis, Hanna, and Philbrick (1997); and International Organization of Securities Commissions (2003). Boni and Womack (2002) cite several press reports and the testimony of the (then) acting SEC chairman Laura Unger to the House Subcommittee on July 31, 2001.
} 
choose to cover companies they judge favorably, hoping that those are of most interest to their clients. If they do not account for winner's curse, their recommendations will be too positive.

Previous literature has shown that analyst recommendations are, indeed, systematically shifted upward. We confirm this pattern in our data. Table I displays the sample statistics of affiliated and unaffiliated recommendations for the entire sample period (October 1993 through December 2002), containing 121,130 recommendations. There are 8,466 (7\%) affiliated recommendations. Affiliated analysts issue more positive recommendations than unaffiliated analysts. The average recommendation level for any type of affiliated analyst lies around 4, i.e., is at least a "buy." For unaffiliated analysts, the average is statistically significantly lower, at 3.76. Likewise, the mode is "buy" for affiliated analysts but "hold" for unaffiliated analysts.

Analysts make very few sell and strong sell recommendations (4.58\%), regardless of their affiliation, but affiliated analysts make even fewer. For example, analysts with IPO and SEO lead and co-underwriter affiliations issue a total of only 154 sell and strong sell recommendations. Affiliated recommendations are significantly higher than unaffiliated ones over the entire sample, but the difference is even stronger before 2002. These differences do not arise from quicker reaction to news. As shown in Malmendier and Shanthikumar (2004), affiliated analysts update their recommendations more slowly (every 357 days) than unaffiliated analysts (every 308 days). While affiliated analysts update negative and hold recommendations faster, they preserve positive recommendations about 70 days longer than unaffiliated analysts.

We also consider separately independent brokerage firms, which do not underwrite any securities, starting five years before our sample period (1987-2002). Such "never-affiliated" brokerages have no corporate finance department and are easily identifiable, even by small investors. Using this definition, $5.3 \%$ of the recommendations $(6,418)$ in our sample are independent. Independent analysts make the most sell and strong sell recommendations. Their average recommen- 
dation is significantly lower than for unaffiliated analysts (by -0.0622 , with a standard error of 0.0119) or any other group of affiliated analysts (the difference to all affiliated analysts is 0.3102 , with a standard error of 0.0157$)$. As a robustness check, we classify analysts as independent if they have no underwriting affiliation during the five years prior to a recommendation, which applies to $15.3 \%$ of recommendations $(18,486)$. This definition has the advantage of including information only up to the recommendation date and the disadvantages of failing to capture "true independence" (the additional 10\% have a corporate finance department) and being harder to identify by small investors. We replicate all results using the alternative measure.

Finally, we test whether the more positive recommendations of affiliated analysts reflect differences in the firms they cover. Companies that have recently issued securities might be better investments, as evidenced by their access to capital markets. In Panel B of Table I, we restrict the sample to firms that have recently issued stocks or bonds. The statistics are virtually identical. In addition, a detailed comparison of the distribution of covered stocks across the National Association of Investors Corporation (NAIC) industries reveals very close similarities. The portion of affiliated and unaffiliated recommendations falling into any of the NAIC industry groups differs by less than one percentage point for all but three industries.

In summary, recommendations display two types of bias. First, more than $95 \%$ are positive or neutral. Second, recommendations are even more positive if the analyst is affiliated.

\section{Trade reaction}

How do investors react to recommendations? We distinguish between large and small investors and ask how they account for the two types of distortions.

\subsection{Measuring trade reaction}

We measure the trade reaction to recommendations with the directional trade-initiation measures of Lee and Ready (1991). "Buyer (seller) initiated" means that the buyer (seller) demands 
immediate execution, generally representing a market order, which is to be executed immediately at the current market price. Thus trade initiations capture buy and sell pressure.

We use the modified version of the Lee-Ready algorithm developed by Odders-White (2000). The algorithm matches a trade to the most recent quote that precedes the trade by at least five seconds. If a price is nearer the ask price it is classified as buyer-initiated; if it is nearer the bid price, it is classified as seller-initiated. If a trade is at the midpoint of the bid-ask spread, it is classified based on a "tick test." The tick test categorizes a trade as buyer-initiated (selleriniated) if the trade occurs at a price higher (lower) than the price of the previous trade, i.e., on an uptick (downtick). We drop trades at the bid-ask midpoint, which is also the same price as in preceding trades.

As a proxy for net buy pressure, we consider three measures. The net number of buyerinitiated trades for firm $i$, investor type $x$, and date $t$ is defined as

$$
N B_{i, x, t}=\text { buys }_{i, x, t}-\text { sells }_{i, x, t}
$$

The raw trade imbalance measure for firm $i$, investor type $x$, and date $t$ is calculated as

$$
T I_{i, x, t}=\frac{\text { buys }_{i, x, t}-\text { sells }_{i, x, t}}{\text { buys }_{i, x, t}+\operatorname{sells}_{i, x, t}}
$$

We normalize this measure by subtracting the firm-year mean and dividing by the firm-year standard deviation, separately for each investor type, as in Shanthikumar (2003):

$$
T I_{i, x, t}^{\text {abnormal }}=\frac{T I_{i, x, t}-\overline{T I}_{i, x, \text { year }(t)}}{S D\left(T I_{i, x, y \text { ear }(t)}\right)}
$$

The adjustments are made by year to account for changes in trading behavior over time and by firm to account for differences in small and large trading behavior for different stocks. These normalizations allow us to compare trading behavior over time and among firms and replace year- and firm-fixed effects in the regression framework. 
As a robustness check, we also replicate our analysis using the number of shares or the dollar amount of trades rather than the number of trades.

\subsubsection{Ownership}

Trade initiation is different from "making a trade." It captures how urgently investors want to trade. While investors place limit orders for reasons such as liquidity trading, trade initiation indicates that an investor has a strong belief about future stock price movements.

The algorithm for trade initiation does not identify the other side of the trade. A buyer-initiated large trade, for example, could be filled with a large non-initiated sell order, with several small trades that are pulled together, or by the market maker. Thus, trade imbalances do not necessarily lead to ownership changes between different investor groups.

In order to test whether or not trade imbalances predict ownership changes in our data, we compare them to changes in institutional ownership in the CDA/Spectrum Institutional Holdings data (13f SEC filings). Since the data are quarterly, we aggregate the trade measures over the corresponding quarters. Table II displays correlations with ownership change. We find that largetrader buy pressure is significantly correlated with an increase in institutional ownership, and small-trader buy pressure with a decrease. The results are even stronger if we adjust for time trends in institutional ownership by removing the average ownership change in a given quarter. We also find consistent results when measuring the correlations for each quarter separately. Despite the loss of power, the correlation of the sum of daily trade imbalances and institutional ownership is significant at the $10 \%$ level in 21 of the 36 quarters, in the expected directions.

To gauge the economic significance of these correlations, we regress the quarterly changes in institutional ownership on the quarterly sum of large-investor trade imbalances and a constant. We find that an increase of one standard deviation in the summed large trade imbalances more than doubles the average increase in institutional ownership, from $0.4 \%$ to $0.86 \%$. Thus, trade 
imbalance corresponds to statistically and economically significant changes in ownership composition, as far as we can infer from the quarterly institutional ownership data.

\subsection{Trade reaction of small and large investors}

To analyze trade reactions to recommendations, we distinguish trading on the first two days at or after recommendation issuance (event days 0 and 1 ) from the remaining sample period.

Table III presents summary statistics. Panel A shows that, over the full sample period, small investors execute 8.49 more buyer-initiated trades and 8.73 more seller-initiated trades per day than large investors. The average differences between buyer- and seller-initiated trades are very similar, 3.18 for small trades and 3.43 for large trades. The median difference is zero for both small and large trades. During the two event days, the differences between buys and sells are considerably higher, 19.26 for small trades and 18.92 for large trades (Panel B). Thus, recommendations induce systematic buy-pressure among all investors - a first indication that they have informational value even for large investors, consistent with Barber et al. (2001) and Jegadeesh et al. (2004). The normalized trade imbalance for large traders is slightly negative (unnormalized it is slightly positive, 0.058 ), indicating that large portion of trades initiated by large traders on event days are for firms with high average trade imbalances.

In Table IV, we regress the normalized abnormal trade reaction on dummies for each recommendation level and interactions with an affiliation dummy, separately for large and small traders. The coefficients of the five level effects show the reaction to unaffiliated recommendations, and the five interactions show the differential reaction if the analyst is affiliated. In a third column, we report the difference between large and small investors' trade reaction. All standard errors are adjusted for heteroskedasticity and arbitrary within-event-date correlation.

The first four panels (upper half of Table IV) show the regression results for the full set of all recommendations during our main sample period (February 1994 through July 2001) and three 
subsamples: 1) excluding three-day windows around earnings announcements; 2) excluding reiterations; and 3) excluding both earnings announcements and reiterations. Subsample 1 allows us to distinguish the effect of recommendations from the effect of simultaneous earnings announcements. We consider a plus-or-minus one-day window around the announcement date, since the reaction of small traders is strongest on days 0 and 1 after the announcement (Battalio and Mendenhall, 2005; Shanthikumar, 2003). Using the IBES data on earnings announcements to identify the overlapping dates, ${ }^{7}$ we find that $12 \%$ of recommendations occur during the three trading days around earnings announcements, similar to the joint distribution of recommendations and earnings announcement in Womack (1996). Subsample 2 separates out reiterations, which should have little or no informational content and thus no impact on trades. When identifying reiterations we account for the left-censoring of the data by dropping the first 179 days of the IBES sample period (i.e., before April 26, 1994), as described in Section 2.1. Subsample 3 combines the restrictions of Subsamples 1 and 2.

In the full sample (first three columns), large investors' reaction to unaffiliated recommendations is significantly positive for strong buy recommendations, insignificantly positive for buy recommendations, and significantly negative for hold, sell, and strong sell recommendations. Small investors, instead, display significantly positive reaction to both buy and strong buy recommendations and zero trade reaction to hold recommendations. They display negative abnormal trading responses only to sell and strong sell recommendations.

The implications of these baseline results are two-fold. First, recommendations have a significant impact on the trading behavior of both large and small investors. Second, large traders ac-

\footnotetext{
${ }^{7}$ The quality of matches between recommendations and earnings announcements is high: $99.35 \%$ of the recommendations have a matched earnings announcement date within $+/-80$ days. Alternatively, we used the COMPUSTAT data to identify earnings announcement dates. The resulting fraction of matches within the same $+/-$ 80 -day window is lower $(93.69 \%$ ), plausibly due to the lower-quality matching mechanism (six-digit CUSIP rather
} 
count for the upward bias in analyst recommendations by shifting their reaction down by one level (e.g., they hold in response to buy recommendations and sell in response to hold recommendations). Small traders do not adjust their trades but take analyst recommendations literally. The upper part of Fig. 1 ("Unaffiliated Analysts") summarizes schematically the differences in behavior between traders who adjust for the upward distortion (Column 1) and traders who do not adjust (Column 2).

The interaction coefficients in the next five rows show that large investors react significantly less positively to strong buy or buy recommendations if the analyst is affiliated. Their overall reaction is zero (insignificantly negative). The differential reaction to hold, sell, and strong sell recommendations is insignificant. Thus, as with unaffiliated recommendations, they react negatively to neutral and negative recommendations. Small investors, instead, do not display any significant difference in their reaction to positive recommendations if the analyst is affiliated. They react more negatively to affiliated strong sell recommendations.

The results indicate that large traders apply an additional downward adjustment to positive recommendations if the analyst is affiliated. Small investors, instead, do not differentiate between affiliated and unaffiliated recommendations. They take both types of recommendations literally. The lower part of Fig. 1 ("Affiliated Analysts") summarizes these differences in behavior, displaying the net trade reaction (rather than the differential as in Table IV).

Note that the schematic reaction "without adjustment" (Column 2 of Fig. 1) does not predict that the coefficient of small investors' trade reaction is more negative for affiliated than for unaf- 
filiated strong sells (-0.838 versus -0.105 in Table IV). This result is due to an IBES coding imprecision $^{8}$ and is identified out of an extremely small sample (27).

As in all empirical work on trade reactions, the coefficient of determination is rather low, around $1 \%$, revealing large cross-sectional heterogeneity. Since the focus of the analysis is not to forecast trade volume but to contrast small and large investors' reaction to recommendations, the goodness of fit has a very limited role.

The normalization of our trade imbalance measure also allows us to compare the magnitude across investor groups. The coefficients indicate that small traders react more strongly than large traders to positive recommendations. Their reaction to unaffiliated strong buy recommendations is about two times as large as that of large investors, and their reaction to buy recommendations is about ten times as large. The reactions to negative recommendations are similar in magnitude for both types of investors (except the affiliated strong sell anomaly discussed above). The weaker reaction of large investors could reflect earlier access to information, including front running as discussed below, or additional discounting for the upward distortions.

It is harder to interpret the economic significance of the coefficients. Since the standard deviation of abnormal trade imbalance is normalized to 1 , we can interpret the coefficients*100 as a percentage of the standard deviation. For example, an unaffiliated strong buy recommendation triggers an increase of $11 \%$ of one standard deviation of abnormal trade imbalance among large traders, but $24 \%$ among small traders.

The next three panels (next nine columns in the upper half of Table IV) reveal that the results are not driven by earnings announcements or reiterations. After removing recommendations

\footnotetext{
${ }^{8}$ Some analysts use four instead of five recommendation levels, only one of which is negative. IBES codes the negative level as strong sell. Four categories turn out to be particularly common among affiliated analysts: $30 \%$ of the 27 affiliated recommendations coded as strong sell represent a general sell category. This affects the dynamics of the negative trade reaction. Since analysts most often downgrade in stages, strong sells are typically preceded by
} 
within three days around earnings announcements for the same stock, we estimate very similar coefficients. All coefficients follow the exact same pattern of being significantly positive, significantly negative, or insignificant. The coefficients of the large hold-affiliation interaction and of the small hold dummy switch sign but remain insignificant. For example, while large traders display a significantly negative reaction to unaffiliated holds both in the full sample and in the sample without earnings announcement days (-0.091 with a standard error of 0.011 , and -0.095 with a standard error of 0.012 , respectively), the small traders' reaction changes from small and insignificantly positive $(0.007$, standard error 0.014$)$ to small and insignificantly negative (0.015, standard error 0.014). In both samples, the small-trader coefficient is much smaller in absolute magnitude than the large-trader coefficient. And both differences between the large-trader reaction and the small-trader reaction are highly significant.

The same is true for Subsample 2. After removing reiterations, all 20 estimated coefficients are again of the same direction (or remain insignificant) and of very similar magnitude. Large traders' reaction to buy recommendations is now closer to significant $(0.018$, standard error 0.012) though still an order of magnitude smaller than the small-trader reaction $(0.141$, standard error 0.014). In Subsample 3, where we remove both recommendations around earnings announcements and reiterations, all 20 coefficients have again the same pattern of significantly positive, significantly negative, and insignificant. As with Subsamples 1 and 2, a few coefficients switch sign (large-trader hold and small-trader hold, hold interaction, and strong-buy interaction); but as before, these coefficients are insignificant and small in absolute magnitude. Thus, neither simultaneous information in earnings announcements nor uninformative reiterations appear to be driving our results.

\subsubsection{Initiations, reiterations, upgrades, and downgrades}

sells. Small investors who normally sell "already" in response to the earlier sells rather than the (subsequent) strong 
Prior recommendations affect the informational content of recommendations. For example, upgrades to buy convey more positive information than buy reiterations. To test which types of recommendations are driving our full-sample results, we split the sample into initiations, reiterations, upgrades, and downgrades. As with Subsample 3, we remove the first 179 days of the IBES sample and exclude recommendations within three days around same-stock earnings announcements. The majority of recommendations (43\%) are initiations. Only 5\% are reiterations. The remainder is roughly equally split between upgrades (24\%) and downgrades (28\%). The relative portions of initiations, upgrades, and downgrades are similar to previous studies, e.g., Barber, Lehavy, McNichols, and Trueman (2001). The percentage of reiterations is lower in IBES than in previously used data.

The lower half of Table IV shows the regression results for each subsample. The categories of affiliated sell and strong sell reiterations and affiliated sell upgrades disappear due to lack of data. The category of affiliated sell initiations remains but contains only one recommendation.

We find that the positive reaction to strong buy recommendations, which we estimated for both large and small investors in the full sample, is fairly consistent among all three relevant subsamples. The exception is large traders' reaction to strong buy reiterations, which is insignificantly negative. Small traders, instead, display a significantly positive trade reaction to these reiterations. The coefficients for unaffiliated buy recommendations, for which we estimated a small (insignificantly positive) reaction among large traders and a large (significantly positive) reaction among small traders in the full sample, are more divergent across subsamples. For small traders, the coefficient estimate is positive in every subsample, though insignificant for downgrades. For large traders, we estimate a negative coefficient in the case of reiterations (insignificant and small) and downgrades (significant and large). The initiations estimate is again similar

sells are now coded as reacting to the "strong sells," triggering the higher abnormal sell reaction. 
to the full sample (small, positive, and insignificant), and the upgrades estimate is significantly positive. Overall, as shown in columns "Difference S-L," large traders react significantly less positively to buy and strong buy recommendations than small traders in every subsample.

For unaffiliated holds, we find that the negative reaction of large traders, which we estimated on the full sample, reflects a large negative response to downgrades (-0.162) and initiations (0.033). The response is insignificant for reiterations and upgrades. Small traders' reaction to holds is instead small and insignificant in every subsample.

Unaffiliated sell and strong sell recommendations, for which we estimated negative trading responses for both types of investors, trigger the strongest negative response in the downgrades sample. Most other coefficient estimates are also negative though typically insignificant.

Turning to the differential reaction to affiliation, we find that the discounting of large traders after positive recommendations replicates in the initiations sample. In the other subsamples (and for other recommendation levels), the interaction coefficient is insignificant, with two exceptions: the coefficient on affiliated sell initiations is large and significantly negative, though identified out of one observation; the coefficient on affiliated upgrades to hold is also significantly negative. For small traders we estimate mostly insignificant differential trading responses, with four exceptions: the differential reaction to sell initiations is significantly negative, that to affiliated strong buy reiterations significantly negative, and that to buy and strong buy upgrades significantly positive. The first result is estimated out of a single observation. The others remain puzzling. They reveal, however, that upgrades are driving the "affiliation neglect" of small traders, while initiations are driving the "affiliation adjustment" of large traders.

In summary, we can link the full-sample estimates to three main subsample results. First, the key results replicate in the initiations subsample. Large traders react less positively than small traders to unaffiliated hold, buy, and strong buy recommendations, and they discount positive 
recommendations even more if the analyst is affiliated. Sell and strong sell initiations, however, trigger insignificant responses by both large and small traders. The less negative and less significant reaction relates to the results in Bradley, Jordan, and Ritter (2003): initiations right after the quiet period trigger less response; later initiations trigger a particularly positive response.

Second, reiterations cause no statistically significant trading response among large traders. For large traders, the negative coefficient of the hold-affiliation interaction, -0.288 , is closest to significant with a t-statistic of 1.43 . All others are even farther from significant, with t-statistics between 0.15 and 0.88 . By contrast, reiterations trigger a significantly positive reaction among small traders in the case of unaffiliated buy and strong buy recommendations. Thus, small traders appear to account less for the informational content of recommendation changes.

Third, for a given recommendation level, large traders react more positively to upgrades and more negatively to downgrades. Small traders' reaction is less closely aligned with the direction of changes, e.g., when displaying an insignificantly positive (rather than significantly negative) reaction to downgrades from strong buy to buy. Small traders do react significantly more positively to upgrades than to downgrades in the case of buys (t-statistic 4.64) but not in the case of hold recommendations (t-statistic 1.43). ${ }^{9}$ As mentioned above, the results for strong sell recommendations are more mixed, possibly due to the small sample sizes. (Only $2.6 \%$ of the 1,172 strong sells are reiterations; $23.6 \%$ are initiations; the remainder are downgrades.)

\subsection{Robustness}

We perform several robustness checks of the documented trading behavior.

\subsubsection{Econometric model}

\footnotetext{
${ }^{9}$ Note that the negative sell-coefficients in the upgrades, reiterations, and initiations sample are larger than in the downgrades sample but insignificant for upgrades and reiterations. The estimation is affected by the extremely small sample size of the identifying subsample. There are only 64 upgrades to sell and 49 reiterations of sell recommendations, while there are 1,283 downgrades to sell and 398 initiations at the sell level.
} 
Panel A of Table V reestimates the standard errors, allowing for heteroskedasticity and arbitrary within-year correlation (columns marked "Cluster by Year") and arbitrary within-brokerage firm correlation (columns marked "Cluster by Brokerage Firm"). Clustering by year allows for a wider range of cross-correlations than our primary method (clustering by date), although the low number of clusters is problematic (Wooldridge, 2002; Froot, 1989). Our results are robust to these alternative assumptions. Large investors adjust downwards and display a sell reaction to hold and no reaction to buy recommendations. They also react more negatively to affiliated than to unaffiliated strong buy recommendations, although the downward adjustment is not significant for buy recommendations. The abnormal trade reaction of small investors follows again a literal (unadjusted) interpretation of recommendations and does not differentiate between affiliated and unaffiliated recommendations (as before with the exception of strong sells).

We also repeat the regressions of Table IV including year- and brokerage-fixed effects. Alternatively, we include year-firm interactions, adding more than 20,000 fixed-effects groups, in order to capture firm characteristics that change over time. As expected, given that the measure of trade imbalance is normalized on a firm-year basis, the results do not change.

\subsubsection{Investor type classification}

We check the robustness to several variations in the cutoff values for trade size (Table V.B): $\$ 1-\$ 5,000, \$ 5,000-\$ 10,000, \$ 10,000-\$ 20,000$, and $\$ 20,000-\$ 50,000$. Our baseline small-investor cutoff aggregates the first three groups. Both sets of results for small traders - the literal reaction to recommendations and the lack of adjustment for affiliation — replicate in almost all cells. The largest group $(\$ 20,000-\$ 50,000)$ behaves more like large investors. Traders discount positive recommendations if the analysts are affiliated. The interaction coefficients for buy and strong buy are significantly negative. Moreover, the puzzling differential trade reaction to affiliated strong sells, which we found in Table IV, loses significance in the largest group. On the 
other hand, the reaction to negative unaffiliated recommendations becomes insignificant in two subgroups (below $\$ 5,000$ and $\$ 20,000-\$ 50,000$ ). Overall, both results show remarkable robustness within each of these small subgroups.

\subsubsection{Measure of trade reaction}

The results are similar if we employ the net number of buyer- minus seller-initiated trades or the raw trade imbalance. Also, using normalized imbalances of shares traded or of dollar amounts traded (rather than trades) produces similar results: 19 of the 20 coefficients and all ten differences between small and large traders display the exact same pattern of significantly positive, significantly negative, or insignificant. Only the large-trader interaction of affiliation and buy recommendations changes, to insignificantly negative.

Longer horizons (up to 20 trading days after the recommendation) also lead to similar results. Finally, we limit the sample to firms that have at least some institutional ownership at the quarter-end before the recommendation, using several different cutoffs, as large trading is most likely to be from institutions for these firms, and find similar results.

\subsubsection{Affiliation}

We also perform several robustness tests of our affiliation classification. First, we split "affiliation" into its component parts, and we use the additional forms of affiliation, future underwriting and bond underwriting. Second, we specify whether a firm has recently issued a security and whether the underwriter is independent. Third, we repeat the baseline regression separately for each year in the sample. With all of these variations, the primary results remain.

\subsubsection{Relationship between investor yype and affiliation}

Another concern is that investors systematically lower their trading size in response to affiliation. The resulting (re-)classification of large investors as small could generate their weaker reaction to affiliated buy recommendations. 
An immediate weakness of this alternative explanation is that it cannot explain our first result, i.e., that small investors do not discount analyst recommendations on average. Two additional results address the concern directly. First, systematic shifts in trade size that are large enough to move investors normally trading above $\$ 50,000$ into the class of trades below $\$ 20,000$ should be reflected in the remaining class of large trades. For example, a uniform shift would reduce the average size of the large trades by at least $\$ 30,000$. However, the average size of large trades is $\$ 217,244$ in response to unaffiliated recommendations and $\$ 209,836$ in response to affiliated recommendations, a reduction of less than $3.5 \%$.

Second, in order to explain the more negative reaction of large traders in response to affiliated recommendations, a general reduction of trade size does not suffice. Rather, the proportion of buy-initiators among large traders has to go down. Instead, both changes are small and similar. Buyer-initiated large trades change on average by $3.9 \%$ and seller-initiated large trades by $2.5 \%$.

\subsubsection{Analyst heterogeneity}

The differences in trading responses could arise if small investors follow different (more affiliated) analysts than large investors. To address this concern, we reduce the heterogeneity of recommendations and consider only those issued by brokerages that are both affiliated and unaffiliated at different points during the sample period ("Ever-Affiliated Brokerages," Columns 1 to 3 in Table VI). All results replicate, for both large and small traders.

As a second way to address heterogeneity, we restrict the analysis to analysts who were listed in Institutional Investor's most recent October list of top analysts (“All Star Team," Columns 4 to 6$).{ }^{10}$ The resulting sample is significantly smaller (11,882 observations), but most results replicate. Exceptions are the differential response of large investors to affiliated buys (now insignificant) and of small investors to affiliated strong buys (now marginally significant with $\mathrm{t}=$ 
1.821 in the All-Star sample). The reaction to negative recommendations also loses significance in several instances. Overall, the core results replicate in both subsets and analyst heterogeneity and adverse sorting of small investors appear unlikely to generate our results.

\subsubsection{Brokerage firm heterogeneity}

Even if small investors do not follow worse analysts, they may only be aware of more widely known brokerage firms. To address this concern, we obtain sales and employee data for brokerages from the Dun \& Bradstreet Million Dollar Database, which is available for about 5\% of our sample. We control for brokerage size by interacting every level of recommendation with sales or with the number of employees as proxies for size. In unreported regressions, we find that the inclusion of size controls does not diminish the results beyond the effect of the reduced sample.

\subsubsection{Front running of large investors}

Another important concern is that large investors might trade prior to recommendations. If they learn the information that sparks new recommendations earlier, their trade reaction could take place earlier. At the time of the recommendation, they then display either no reaction or a contrarian reaction, explaining their lower event-time trade reaction.

In order to test for front running, we calculate the average daily trading volume of large investors during the month prior to the recommendation. All averages - number of trades, shares traded, and dollar volume traded — peak on the day of the recommendation and not before. We also observe a slow increase over time. This trend could reflect anticipatory trading before the release of the recommendation or a response to general news about the stock. To distinguish these explanations, we re-analyze the relation between recommendation and trade imbalance, as in Table IV, for the week preceding recommendations (days -5 to -1 ). None of the coefficients implies anticipatory trades among large traders. Instead, large traders exhibit a significant buy-imbalance

\footnotetext{
${ }^{10}$ We thank Steven Drucker for providing us with the 1995-2001 lists of "All Star" analysts. We obtained the
} 
for "downgrade buys," i.e., stocks that are currently strong buys but will be downgraded to buy within the next five trading days, while they exhibit a significant sell-imbalance once the downgrade occurs. Similarly, they exhibit insignificant negative pressure before an upgrade to strong buy, but significant buying pressure when the upgrade occurs. These results remain unchanged when we include a larger event window.

\section{Interpretation}

What explains small investors' lack of adjustment to 1) the general upward bias and 2) the specific upward bias of affiliated analysts? One potential reason is different information costs. If it is less costly for institutional investors than for individuals to find out about analyst distortions, only institutions might choose to acquire the information. An alternative explanation, which we dub investor naiveté, is that some small investors fail to adjust their trades even to freely available information about analyst distortion, or that they underinvest in information acquisition.

Evaluating the different explanations requires measures of the cost of information and the return implications of the trading responses. If costs are zero or low enough that it would increase small trader's utility if they acquired the information, there is room for investor naiveté. Otherwise, we can explain their behavior in the standard rational framework.

Such an evaluation is difficult to perform. First, it is hard to measure the costs of obtaining information. Second, measuring the returns to information requires information about the portfolios of small investors, which is not contained in our data. Third, even if we could measure the returns, they do not easily translate into utility. Nevertheless, a few additional results shed some light on the costs and benefits of information and thus the plausibility of the explanations.

\subsection{Benefits of information about analyst distortion}

names for the remainder of our sample period using the October issues of Institutional Investor Magazine. 
A plausible proxy for the benefits of adjusting to analyst distortion is the difference in returns earned by small and large investors' trade reactions, neglecting their (possibly heterogeneous) translation into utility. However, our data do not reveal portfolio choices. For example, we do not observe the typical holding period in response to different types of recommendations. As a second best, we use trade imbalances to approximate the trading strategies in two ways.

\subsubsection{Trade reaction and event returns}

First, we test whether the direction and strength of buy or sell pressure among each investor group predicts event returns. We use buy-and-hold returns net of the value-weighted CRSP market returns. The market-adjusted return of stock $j$ on day $t$ is

$$
A_{j t}=R_{j t}-R_{m t}
$$

We regress the abnormal return on a constant and on the dollar value of net buyer- minus sellerinitiated trades on event days 0 and 1 . We perform this analysis over three, six, and twelve months after each recommendation. As shown in Table VII, Panel A, abnormal trades by small investors predict significantly negative returns over the six-month horizon and insignificantly negative returns over three and twelve months (with p-values of $13 \%$ and $10 \%$, respectively). Large traders' trade reaction predicts instead significantly positive abnormal returns over all horizons. The difference between the coefficients for large and small traders is significant for six and twelve months and insignificant (at a p-value of 12\%) for three months. Thus, if we assume holding periods of six or twelve months, small traders incur losses relative to large traders from their reactions to recommendations. The estimated loss is not significant for three months.

\subsubsection{Analyst recommendations and portfolio returns}

Our second approach is to examine the returns to investment strategies that follow analyst recommendations "literally": if an analyst issues a buy or strong buy recommendation, the investor purchases the stock in the long portfolio; if the analyst issues a sell or strong sell recommenda- 
tion, the investor sells (shorts) the stock in the short portfolio. We consider holding periods of three, six, and twelve months. A stock is dropped from the portfolio when the analyst revises the recommendation to any level other than hold, stops covering the stock, or when the holding period expires. If an analyst issues a hold recommendation during the holding period of a stock, the holding period restarts. If multiple analysts make the same type of recommendation for the same stock, the stock appears in the portfolio multiple times. The portfolio is reevaluated daily. Changes occur at the end of the trading day of the corresponding recommendation event. We split the analysis into affiliated and unaffiliated recommendations. ${ }^{11}$ Whenever the short portfolio is empty, we drop it from our calculations. We use the Fama-French four-factor portfolio method to determine value-weighted buy-and-hold abnormal returns separately for the long and the short portfolio, estimating

$$
R_{i t}-R_{f t}=\alpha_{i}+\beta_{i}\left(R_{m t}-R_{f t}\right)+s_{i} S M B_{t}+h_{i} H M L_{t}+u_{i} U M D_{t}+\varepsilon_{i t}
$$

where $R_{i, t}$ is the return of portfolio $i, i \in\{$ Buy, Sell $\}$, on day $t ; R_{m, t}$ is the return of the market portfolio on day $t ; R_{f, t}$ is the risk-free rate on day $t$; $S M L, H M L$, and $U M D$ are the size, book-tomarket and momentum factors; ${ }^{12}$ and $\alpha_{i}$ estimates the (gross) abnormal return. For the short portfolio, we multiply all coefficients by -1 to display the returns to selling rather than buying.

We calculate the net daily abnormal returns by subtracting the estimated brokerage commission and bid-ask spread. We apply the $\$ 30$ (online) per-trade commission at Charles Schwab during our sample period to the average trade size of small investors, $\$ 8,971.73$. We add the $1 \%$ cost of the bid-ask spread estimate of Barber and Odean (2000) for individual investors, and es-

\footnotetext{
${ }^{11}$ The unaffiliated long portfolio contains, on average, 1,571, 2,835, and 4,617 stocks for the holding periods of three, six, and twelve months; the affiliated long portfolio contains only 107, 197, and 328 stocks on average for the same horizons. The affiliated long portfolio is missing for the first day of our sample period, since no affiliated recommendation was issued. Similarly, the unaffiliated short portfolio consists of 103, 184, and 285 stocks, on average, while the affiliated short portfolio is empty for 201 days and contains, on average, only two stocks during the remaining 1,690 days, for the three-month horizon; it is empty during 24 days, with an average of four stocks, for the six-month horizon, and it is empty for twelve days, with an average of five stocks, for the twelve-month horizon.
} 
timate total transaction costs of $1.669 \%$. (We neglect the market impact of trading, which would further increase the transaction cost.) We apply the transaction cost estimate to the daily turnover of each portfolio. ${ }^{13}$ Note that the volume of trading, while not excessive, likely exceeds realworld trading of most small investors. However, since we neglect the market impact of trading and since we use the size of actual trades in our sample to estimate trading commissions, our transaction cost estimate is conservative relative to the, say, 2.99\% roundtrip commission in Barber and Odean (2000), restricting the transaction cost estimate. We also recalculate returns for a similar strategy with only monthly rebalancing, with even stronger results (see below).

Panel B of Table VII presents the daily returns (in \%) of the resulting portfolios. In the long portfolio, gross abnormal returns are insignificantly positive for unaffiliated recommendations and mostly negative and insignificant for affiliated recommendations. Accounting for transaction costs, the returns are always negative and, in three out of six cases, strongly significant, with tstatistics between 1.94 and 3.25 (otherwise between 0.18 and 1.49). In each case, the abnormal returns are worse in the portfolio of affiliated analysts than the portfolio of unaffiliated analysts. In the short portfolio, selling stocks with negative recommendations induces negative abnormal returns both gross and net of transaction costs in each of the six portfolios, though significantly so only in three cases after transaction costs. Here as well, the estimates are always more negative for affiliated than for unaffiliated analysts, but the differences are not significant.

All results are similar and more significant when using later transaction dates, e.g., the end of the first day or the end of the second day after the recommendation. The abnormal returns deviate at most by $0.008 \%$, except for the affiliated short portfolio, which deviates by up to $0.014 \%$.

\footnotetext{
${ }^{12} S M L, H M L, R_{m, t}$ and $R_{f, t}$ are from Ken French's website; daily $U M D$ factors are from Jeffrey Busse.

${ }^{13}$ To calculate turnover, we construct a comparison portfolio with no rebalancing from the previous day; the only changes in weight are due to returns. We obtain the difference for each stock between the actual weight and the hypothetical weight without rebalancing and sum the positive differences. By summing only the positive differences, we avoid double-counting and can apply the full round-trip transaction cost directly. The average daily turnover
} 
Gross abnormal returns are lower in most cases, and net abnormal returns are significantly negative at the $1 \%$ level in seven of the twelve portfolios.

The results are also stronger if we use monthly instead of daily rebalancing. We consider a strategy of updating only once a month while still taking recommendations "literally." At the end of each month, the investor trades on recommendations made during that month. Despite the lower turnover, the net returns are still significantly negative. Moreover, the gross return estimates are more consistently negative: the returns from buying any of the three affiliated long portfolios and the returns from selling any of the six (affiliated and unaffiliated) short portfolios are negative, though insignificant. The affiliated portfolio performs always worse than the corresponding unaffiliated portfolio. The difference is significant for the three-month long portfolio.

We also calculate the returns of the zero-investment portfolios constructed from the long and short portfolios in Table VII, Panel B. The abnormal returns are negative over any horizon, insignificantly so before transaction costs, and significantly in all but one case after transaction costs. The differences between returns to the affiliated and the unaffiliated portfolios widen, relative to the separate long and short portfolios, though they remain insignificant. The losses from following affiliated recommendations are sizable, with stable negative abnormal returns of $0.04 \%$ to $-0.07 \%$ before transaction costs and $-0.10 \%$ to $-0.12 \%$ after transaction costs. The returns of the unaffiliated zero-investment portfolio amount to one-third to two-thirds of those magnitudes. $^{14}$

Finally, we repeat the analysis separately for stocks with low institutional interest. If small investors affect stock prices, we would expect their impact to be larger on such stocks and, thus,

ranges from 0.0064 (for the unaffiliated long portfolio with a one-year holding period) to 0.0270 (for the affiliated long portfolio with a three-month holding period).

${ }_{14}$ The returns of the zero-investment portfolio are to be taken with caution given the small number of stocks in the short portfolio. The average number of "holdings per day" in the long portfolio over those in the short portfolio range from 17:1 to $21: 1$ for unaffiliated analysts and 67:1 to 100:1 for affiliated analysts. 
the returns to their trading strategy to be more negative than for the full universe of stocks. We use two proxies for low institutional interest: 1) stocks in the lowest decile of market capitalization as of the first trading day in a year and 2) stocks covered by only one analyst as of the day of recommendation issuance. The smallest stocks tend to get less institutional interest due to higher transaction costs and regulatory implications of large ownership (e.g., Keim and Madhavan, 1998). Low coverage is a direct proxy for low institutional interest.

Reestimating the model of Eq. (4) separately for each level of recommendation in both subsets of stocks, we find that buy and hold recommendations earn large negative abnormal returns over most horizons. The results are significant even before transaction costs for half of the horizonaffiliation combinations in the case of holds and for a few in the cases of buys.

To sum up, we find significantly negative abnormal portfolio returns to following analyst recommendations literally without accounting for transaction costs for stocks with low institutional interest (small and low-coverage stocks). For the overall sample, transaction costs are crucial in turning the mostly negative but insignificant abnormal portfolio returns into significantly negative abnormal returns. Thus, we do not find clear evidence of losses from failing to account for analyst distortions prior to transaction costs.

Our findings confirm, however, the message of Barber and Odean (2000) that "trading is hazardous to [retail investors'] wealth." One way to interpret our results is that investors would earn significantly higher returns if they forwent trading in response to analyst recommendations. An alternative interpretation is that small investors trade anyhow — with or without recommendations. In other words, recommendations might not be the cause of excess transaction costs.

To evaluate the importance of recommendations for excessive trading, we compare the trade reaction they trigger to the impact of other determinants of trading: same-day abnormal volume and prior-day return, as analyzed in Barber and Odean (2006). Same-day abnormal volume is the 
current day's trading volume, normalized by the the stock's prior-year average daily trading volume; prior-day return is the prior trading-day raw return, both as reported in CRSP. For each day, we independently sort stocks into deciles of abnormal volume and prior-day return, and we count the number of recommendations of a given level made for the stock on the same day.

We regress abnormal trade imbalance of small traders, separately, on indicator variables for the decile category of abnormal volume, for the decile category of prior-day return, and on our recommendation count variables. The (unreported) results for abnormal volume and prior-day return are similar to the Barber and Odean results. Abnormal volume is a strong (monotonic) predictor of abnormal buying. Prior-day return is a significant though weaker (and U-shaped) predictor of returns. The highest and lowest trade imbalances due to same-day volume occur in the highest and lowest volume decilse and amount to 0.0615 and -0.0780 . The highest and lowest trade imbalances due to prior-day returns are 0.0679 (for the lowest returns decile) and -0.0271 (in the fifth decile). In comparison, a single buy recommendation raises the abnormal trade imbalance by 0.0323 and a strong buy recommendation by 0.0613 . Limiting the sample to stockdays with recommendations, we find that a single buy recommendation raises the abnormal trade imbalance by 0.0753 , and a strong buy recommendation by 0.1052 . Even thought these magnitudes are not straightforward to compare, recommendations appear to be nearly as strong a predictor of trading as same-day volume and possibly stronger than prior-day returns. Thus, while the possibility remains that small investors would have traded anyway, the comparison to other triggers of abnormal trade suggests that recommendations are likely an important determinant of "trading too much."

\subsubsection{Results in prior literature}

Our results might at first appear be in contrast with a literature documenting that highly recommended stocks outperform the market (e.g., Womack, 1996; Barber et al., 2001). The differ- 
ence, however, is readily explained with the different strategies. The prior papers form buy portfolios using recommendation consensus, which implies strong recommendations with substantial agreement among analysts. In Barber et al. (2001), for example, the most-recommended portfolio contains stocks on which at least half of the covering analysts have a strong buy and the rest a buy recommendation. This portfolio excludes many of the firms in our long portfolio. In addition, "literal" trading uses recommendation levels rather than changes. Boni and Womack (2006) show that portfolios formed from recommendation changes are more profitable.

In sum, the event returns point to negative return implications of small investors' trade reactions, relative to that of large investors, if we assume six- or twelve-month holding periods. The difference is insignificantly negative over three months. The portfolio returns are insignificant. Thus, a rational model with costly information could suffice to explain small investor behavior. Unfortunately, our return analysis is only suggestive, given the lack of data on trading strategies.

\subsection{Cost of information about analyst distortion}

We evaluate the cost of information in three steps. First, we ask whether small investors are able to access the full set of recommendations. Second, we ask whether the cost of information can explain the general failure to adjust to distortions of all analysts. Third, we ask whether the cost of information can explain the difference in small and large traders' responses to affiliation.

\subsubsection{Information about recommendations}

Recommendations are published in various forms, such as analyst reports, online sources (such as briefing.com, FirstCall of Thomson Financial, and finance.yahoo.com), radio and TV interviews, and news articles. Online resources provide information on averages, industry comparisons, upgrades, and downgrades. In addition, companies post their press releases (including information about issuances and underwriters) online. Investors can get to the releases with a few clicks from the Yahoo! site. 
The increasing convenience of online information suggests that recommendations have become more accessible over time. Over our sample period, however, trade reactions to recommendations do not display any time pattern. The results of Table IV are replicable year-by-year, confirming the view of Michaely and Womack (2005) that recommendations became broadly accessible after the 1980s.

The recommendations available to the general public, however, could differ from those available to large investors. To quantify the accessibility to small investors, we collect information from brokerage publications and websites about their target customer: institutions or individuals. We obtain the information for about $85 \%$ of the brokerage firms. (A significant number of firms have been acquired or dissolved.) Of those, only 16.2\% target institutions (e.g., DSP/Merrill Lynch or SG Cowen). ${ }^{15}$ Even those recommendations are often available to retail clients for two reasons. First, numerous institution-oriented firms have acquired or made minority investments in retail brokerage firms (to have a retail distribution outlet for IPO shares), such as Morgan Stanley acquiring Dean Witter and Salomon Brothers acquiring Smith Barney. Second, retail brokerages allow clients to download reports from firms with which they have partnerships (such as Charles Schwab with Goldman Sachs). Individual investors, therefore, have access to most if not all recommendations in our data.

Given that investors can access a large sample of recommendations, informational costs cannot explain our first finding that small investors fail to adjust for general upward distortion among all analysts. Since $95 \%$ of recommendations are positive or neutral, even small investors

\footnotetext{
${ }^{15}$ We identified, for example, Adams, Harkness \& Hill as serving just institutional clients from their mission statement: "Adams, Harkness \& Hill is one of the largest independent research, brokerage, and investment banking firms serving the institutional market." We identified Alliance as serving both markets from their statement: "At Alliance Capital, we're proud to provide a wide range of investment management services to a diverse group of investors worldwide, including institutional clients, high-net-worth individuals and mutual fund investors." We also used information about the lines of business and services offered. Research firms with only 10-15 analysts that are very specialized in a particular field, e.g., energy or healthcare, typically serve only selected institutional investors.
} 
should be aware of the general distortion. Instead, small investors do not discount recommendations while large investors do. Thus, our first finding is hard to explain in a rational framework, while consistent with investor naiveté.

\subsubsection{Information about affiliation}

Small investors could face substantial costs to find out which analysts are affiliated. These costs are a plausible explanation of our second finding that small investors do not differentiate between affiliated and unaffiliated recommendations.

However, if high information costs are the explanation, small investors should look for lowcost ways to obtain this information. Small investors could focus on analysts who are "independent" and never involved in any underwriting. These firms often advertise their independence. In our data, 105 (27\%) of the 382 brokerage firms never underwrite during the entire sample period (starting in 1987). They issue $5 \%$ of the recommendations. The recommendations of these analysts are less upward-biased than in any other affiliated or unaffiliated subsample (Table I). They also induce less (if any) underperformance, though the differences are not significant. Applying the same portfolio strategy as in Panel B of Table IV, we find that the gross alphas from buying the three long portfolios (over three, six, and twelve months) are up to $0.02 \%$ higher per day. Those from selling the short portfolio are up to $0.07 \%$ higher. ${ }^{16}$

In Table VIII, we test whether small investors attempt to overcome informational constraints by focusing on independent analysts. ${ }^{17} \mathrm{We}$ find that they react less to positive recommendations from independent brokerages, with t-statistics of 1.7 and 1.8 for the buy and the strong buy inter-

\footnotetext{
${ }^{16}$ The differences in alpha are $0.0099,0.0212$, and 0.0149 relative to the three-, six-, and twelve-month affiliated long portfolio; 0.0336, 0.0731, and 0.0698 for the three-, six-, and twelve-month unaffiliated short portfolio; 0.0009, 0.0013 , and -0.0006 for the three-, six-, and twelve-month unaffiliated long portfolio; and $0.0139,0.0271$, and 0.0223 for the three-, six-, and twelve-month unaffiliated short portfolio.

${ }^{17}$ Large investors do not need to focus on independent recommendations since they adjust their trade reaction to the distortions. Nevertheless, we find that large investors do not display any significant downward adjustment to positive recommendations of independent analysts and that they display zero trade reaction (rather than a negative reaction) to independent hold recommendations.
} 
actions, respectively (Column 1). This finding does not appear to be due to the small size of the brokerages. The results also hold for the largest $50 \%$ of firms for which we have sales or employee count data (Columns 2 and 3). ${ }^{18}$

Overall, informational costs are unlikely to explain why small investors do not account for the general distortion of analysts, but are a likely explanation for the undifferentiated reaction to affiliated and unaffiliated recommendations. However, small investors do not appear to choose analyst recommendations in a manner that helps to remedy informational constraints.

\section{Conclusion}

Analysts tend to positively bias the information they provide to investors, as evident in the very low number of sell and strong sell recommendations, in particular by affiliated analysts. While large investors adjust their reaction to hold and buy recommendations downwards, small investors take recommendations literally. Small investors also fail to account for the additional distortion due to underwriter affiliation. Potential explanations are higher costs of information and naiveté about distortions in analyst recommendations. We shed some light on the plausibility of these explanations by evaluating the costs and benefits of information about analyst distortion. Lacking information about portfolio strategies, we are limited to measuring the event returns to net trade imbalances and the portfolio returns to a strategy that takes analyst recommendations literally. The event returns to small traders' net trade reaction are significantly lower than those of large traders if we assume six- or twelve-month holding periods; the difference is insignificant over three months. The portfolio returns are mostly negative but insignificant, at least before transaction costs. The portfolio returns are significantly negative prior to transaction costs for

\footnotetext{
${ }^{18}$ The reduced sample size in Columns 2 and 3 induces a few surprising results, such as the insignificantly positive coefficient on strong sell and the significantly positive interaction coefficient of sell and "never affiliated." These results are driven by minimal sample sizes; e.g., there is only one independent sell recommendation. The
} 
stocks with low institutional interest (small and low-coverage stocks). Thus, many of the return results are consistent with a rational model of small investors' trade reaction, though at best a very noisy proxy for the return implications of the response to recommendations.

It is harder to explain in a standard framework why only large traders but not small investors adjust their trade reaction to the general upward bias of analyst recommendations, given that there seem to be some conditions under which it would be more profitable to make that adjustment and given that the general upward bias is visible to any trader reacting to recommendations. It is also striking that small traders do not focus on analysts from independent brokerages. The latter findings suggest that small investors are naive about the distortions and trust analysts too much.

small-sample anomalies disappear if we keep the full sample and use a triple interaction of "never affiliated" and "top 50\% sales or employees" with the respective recommendation level. 


\section{References}

Barber, B., Lehavy, R., McNichols, M., Trueman, B., 2001. Can investors profit from the prophets? Security analyst recommendations and stock returns. Journal of Finance 56, 531-563.

Barber, B., Lehavy, R., McNichols, M., Trueman, B., 2004. Buys, holds, and sells: The distribution of investment banks' stock ratings and the implications for the profitability of analysts' recommendations. Working paper. UC Davis, Davis, CA.

Barber, B., Odean, T., 2000. Trading is hazardous to your wealth: The common stock investment performance of individual investors. Journal of Finance 55, 773-806.

Barber, B., Odean, T., 2006. All that glitters: The effect of attention and news on the buying behavior of individual and institutional investors. Working paper. UC Davis, Davis, CA.

Battalio, R., Mendenhall, R., 2005. Earnings expectations, investor trade size, and anomalous returns around earnings announcements. Journal of Financial Economics 77, 289-319.

Bhattacharya, N., 2001. Investors' trade size and trading responses around earnings announcements: An empirical investigation. Accounting Review 76, 221-244.

Boni, L., Womack, K., 2002. Solving the sell-side research problem: Insights from buy-side professionals. Working paper. Dartmouth College, Hanover, NH.

Boni, L., Womack, K., 2006. Analysts, industries, and price momentum. Journal of Financial and Quantitative Analysis 41, 85-109.

Bradley, D., Jordan, B., Ritter, J., 2003. The quiet period goes out with a bang. Journal of Finance 58, 1-36.

Brav, A., Lehavy, R., 2003. An empirical analysis of analysts' target prices: Short-term informativeness and long-term dynamics. Journal of Finance 58, 1933-1967.

Brav, A., Lehavy, R., Michaely, R., 2003. Using expectations to test asset pricing models. Working paper. Duke University, Durham, NC.

Chan, L., Karceski, J., Lakonishok, J., 2003. Analysts' conflict of interest and biases in earnings forecasts. NBER Working Paper No. 9544.

Conrad, J., Cornell, B., Landsman, W., Rountree, B., 2004. How do analyst recommendations respond to major news? Working paper.University of North Carolina, Chapel Hill, NC.

Daniel, K., Hirshleifer, D., Teoh, S., 2002. Investor psychology in capital markets: Evidence and policy implications. Journal of Monetary Economics 49, 139-209.

Dechow, P., Hutton, A., Sloan, R., 1999. The relation between analysts' forecasts of long-term earnings growth and stock price performance following equity offerings. Contemporary Accounting Research 17, 1-32.

DellaVigna, S., Malmendier, U., 2004. Contract design and self-control: theory and evidence. Quarterly Journal of Economics 119, 353-402.

Dugar, A., Nathan, S., 1995. The effect of investment banking relationships on financial analysts' earnings forecasts and investment recommendations. Contemporary Accounting 
Research 12, 131-160.

Ellison, G., 2006, Bounded rationality in Industrial Organization. Working Paper. Massachusetts Institute of Technology. Cambridge, MA.

Francis, J., Hanna, J.D., Philbrick, D., 1997. Management communications with securities analysts. Journal of Accounting and Economics 24, 363-394.

Froot, K., 1989. Consistent covariance matrix estimation with cross-sectional dependence and heteroskedasticity in financial data. Journal of Financial and Quantitative Analysis 24, 333-355.

Hanley, K., Lee, C., Seguin, P., 1996. The marketing of closed-end fund IPOs: Evidence from transactions data. Journal of Financial Intermediation 5, 127-159.

Hong, H., Kubik, J., 2003. Analyzing the analysts: Career concerns and biased earnings forecasts. Journal of Finance 58, 313-351.

International Organization of Securities Commissions, 2003. Report of the IOSCO Technical Committee on Analysts Conflicts of Interest (September).

Iskoz, S., 2002. Relative performance and institutional reaction to underwriter analyst recommendations. Working paper. Massachusetts Institute of Technology, Cambridge, MA.

Jegadeesh, N., Kim, J., Krische, S., Lee, C., 2004. Analyzing the analysts: When do recommendations add value? Journal of Finance 59, 1083-1124.

Kaniel, R., Saar, G., Titman, S., 2005. Individual investor sentiment and stock returns. Working paper. Duke University, Durham, NC.

Keim, D., Madhavan, A., 1998. The cost of institutional equity trades. Financial Analysts Journal $54,50-69$.

Kolasinski, A., Kothari, S.P., 2004. Analyst objectivity and investment banking relationships: Evidence on analysts affiliated with M\&A advisors. Working paper. Massachusetts Institute of Technology, Cambridge, MA.

Lakonishok, J., Shleifer, A., Vishny, R., 1992. The structure and performance of the money management industry. Brookings Papers on Economic Activity: Microeconomics.

Lee, C., 1992. Earnings news and small traders: An intraday analysis. Journal of Accounting and Economics 15, 265-302.

Lee, C., Radhakrishna, B., 2000. Inferring investor behavior: Evidence from TORQ data. Journal of Financial Markets 3, 83-111.

Lee, C., Ready, M., 1991. Inferring trade directions from intraday data. Journal of Finance 46, 733-746.

Lin, H., McNichols, M., 1998. Underwriting relationships, analysts' earnings forecasts and investment recommendations. Journal of Accounting and Economics 25, 101-127.

Lin, H., McNichols, M., O’Brien, P., 2003. Analyst impartiality and investment banking relations. Working paper. National Taiwan University, Taipei, Taiwan. 
Malmendier, U., Shanthikumar, D., 2004. Do security analysts speak in two tongues? Working paper. UC Berkeley, Berkeley, CA.

Michaely, R., Womack, K., 1999. Conflict of interest and the credibility of underwriter analyst recommendations. Review of Financial Studies 12, 653-686.

Michaely, R., Womack, K., 2005. Brokerage recommendations: Stylized characteristics, market responses, and biases. In Thaler, R., (Ed.), Advances in Behavioral Finance II, Princeton University Press, Princeton, NJ.

Mikhail, M., Walther, B., Willis, R., 2006. When security analysts talk, who listens? Working paper. Arizona State University, Phoenix, AZ.

Odders-White, E., 2000. On the occurrence and consequences of inaccurate trade classification. Journal of Financial Markets 3, 259-286.

Rajan, R., Servaes, H., 1997. Analyst following of initial public offerings. Journal of Finance 52, 508-529.

Schotter, A., 2003. Decision making with naïve advice. American Economic Review 93, 196201.

Shanthikumar, D., 2003. Small trader reactions to consecutive earnings surprises. Working paper. Harvard University, Boston, MA.

Womack, K., 1996. Do brokerage analysts' recommendations have investment value? Journal of Finance 51, 137-167.

Wooldridge, J., 2002. Econometric Analysis of Cross Section and Panel Data. MIT Press, Cambridge, MA. 
TABLE I. Sample of Recommendations

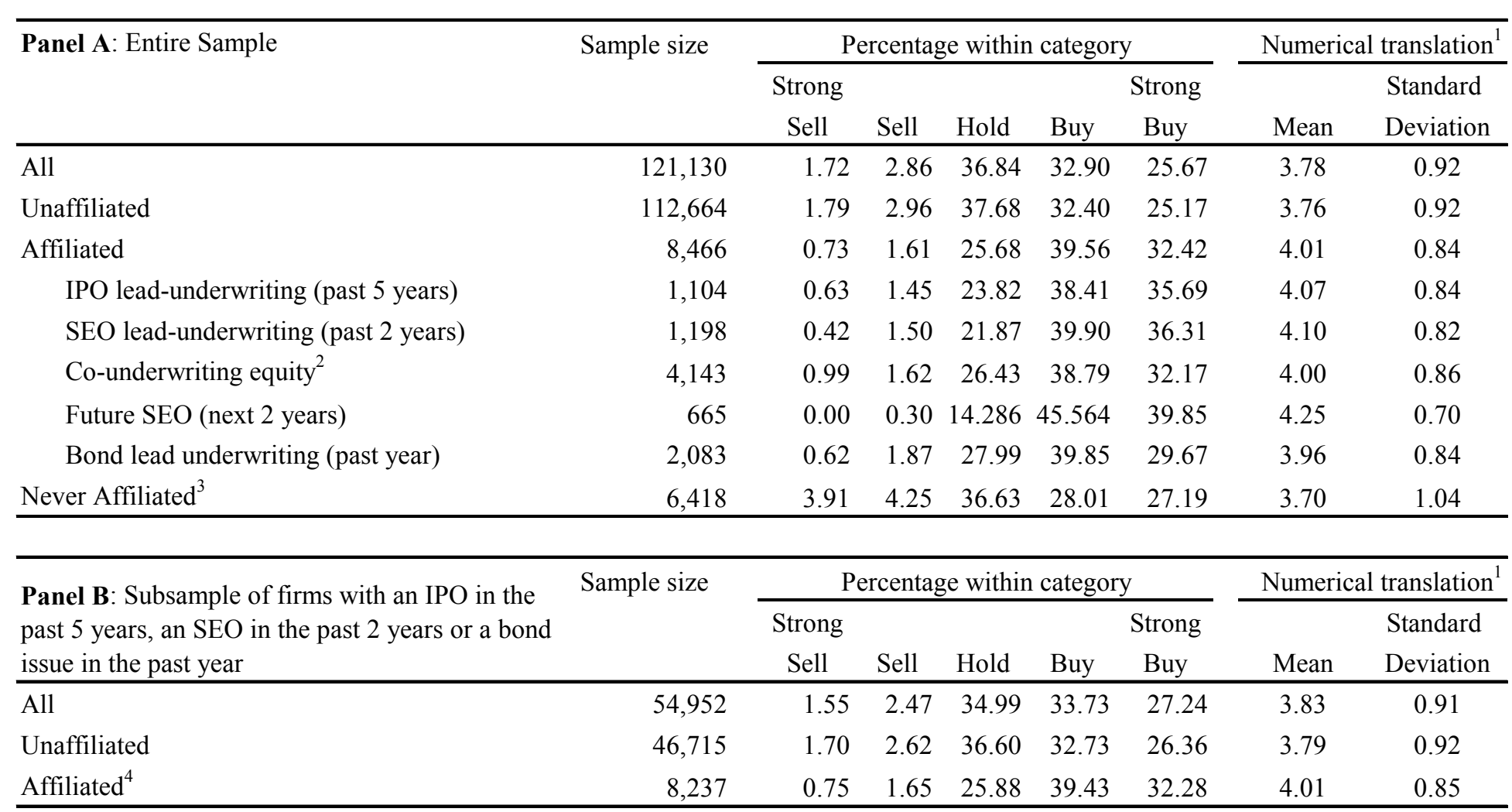

Sample period is $10 / 29 / 1993$ to $12 / 31 / 2002$.

${ }^{1}$ The numerical translation scheme is $1=$ strong sell, $2=$ sell, $3=$ hold, $4=$ buy, $5=$ strong buy.

${ }^{2}$ We exclude co-underwriters who are also lead underwriters of SEO or IPO issuances to eliminate the large number of double-counts in this particular category.

${ }^{3}$ A brokerage firm is "Never Affiliated" if it does not have any (lead or co-underwriter) equity or bond underwriting affiliation during the entire sample period.

4 "Affiliated" summarizes the same categories as in Panel A (IPO in the past 5 years, SEO in the past 2 years, IPO/SEO co-underwriting over the same horizons, future underwriting in the next 2 years, and bond underwriting in the past year). 


\section{TABLE II. Correlations of Institutional Ownership and Trades}

Correlations of the change in the percentage of shares outstanding owned by institutions (as of 13f SEC filings) and measures of trade reaction. Correlations are calculated using all sample firm-quarters from 12/1993 to 12/2002 with both recommendations data and trading data. P-values in parentheses.

\begin{tabular}{lcc}
\hline & Small Investors & Large Investors \\
\hline $\begin{array}{l}\text { Sum of daily abnormal } \\
\text { trade imbalances over last }\end{array}$ & -0.073 & 0.070 \\
& $(0.000)$ & $(0.000)$ \\
& & \\
$\begin{array}{l}\text { Quarterly trade } \\
\text { imbalance, } \\
\text { number of trades }\end{array}$ & -0.082 & 0.088 \\
& $(0.000)$ & $(0.000)$ \\
$\begin{array}{l}\text { Quarterly trade } \\
\text { imbalance, }\end{array}$ & \\
number of shares & -0.089 & 0.122 \\
& $(0.000)$ & $(0.000)$ \\
$\begin{array}{l}\text { Quarterly trade } \\
\text { imbalance, }\end{array}$ & & \\
dollar value & -0.085 & 0.119 \\
& $(0.000)$ & $(0.000)$ \\
\hline
\end{tabular}


TABLE III. Measures of Trade Reaction: Summary Statistics

Panel A. Summary Statistics Daily Trading for Sample Firms (2/1994 - 7/2001)

\begin{tabular}{|c|c|c|c|c|c|}
\hline & Mean & Median & Std. Dev. & Min & Max \\
\hline Total number of small trades & 66.10 & 32 & 102.17 & 0 & 3,953 \\
\hline Total number of large trades & 45.55 & 7 & 128.46 & 0 & 3,627 \\
\hline Number of small buy-initiated trades & 29.97 & 13 & 50.98 & 0 & 1,702 \\
\hline Number of large buy-initiated trades & 21.49 & 3 & 62.14 & 0 & 1,911 \\
\hline Number of small sell-initiated trades & 26.79 & 13 & 42.76 & 0 & 2,453 \\
\hline Number of large sell-initiated trades & 18.06 & 3 & 51.09 & 0 & 1,563 \\
\hline Total number of small buy/sell-initiated trades & 56.76 & 26 & 91.06 & 0 & 3,506 \\
\hline Total number of large buy/sell-initiated trades & 39.55 & 6 & 112.42 & 0 & 3,339 \\
\hline$\Delta$ (buy-sell) initiated small trades & 3.18 & 0 & 23.71 & $-1,440$ & 965 \\
\hline$\Delta$ (buy-sell) initiated large trades & 3.43 & 0 & 17.44 & -660 & 791 \\
\hline Dollar value total small trades & 562,641 & 244,263 & 932,865 & 0 & $27,500,000$ \\
\hline Dollar value total large trades & $12,200,000$ & $1,082,491$ & $47,200,000$ & 0 & $6,640,000,000$ \\
\hline Dollar value small buy-initiated trades & 255,760 & 99,175 & 461,493 & 0 & $12,300,000$ \\
\hline Dollar value large buy-initiated trades & $5,579,860$ & 417,750 & $22,700,000$ & 0 & $4,860,000,000$ \\
\hline Dollar value small sell-initiated trades & 228,392 & 98,550 & 387,906 & 0 & $16,000,000$ \\
\hline Dollar value large sell-initiated trades & $4,666,593$ & 382,524 & $18,300,000$ & 0 & $3,120,000,000$ \\
\hline Dollar value total small buy/sell-initiated trades & 484,153 & 204,600 & 828,517 & 0 & $22,700,000$ \\
\hline Dollar value total large buy/sell-initiated trades & $10,200,000$ & 918,875 & $40,000,000$ & 0 & $5,510,000,000$ \\
\hline Dollar value of (buy-sell) small trades & 27,368 & 2,338 & 201,131 & $-10,600,000$ & $8,854,894$ \\
\hline Dollar value of (buy-sell) large trades & 913,267 & 0 & $9,824,109$ & $-1,430,000,000$ & $4,860,000,000$ \\
\hline$N$ & $2,996,265$ & & & & \\
\hline
\end{tabular}

Panel B. Summary Statistics Trade Imbalance - Sum over Event Days 0 and 1

\begin{tabular}{rrrrrr}
\hline & \multicolumn{1}{c}{ Mean } & Median & Std. Dev. & Min & Max \\
\hline$\Delta$ (buy-sell) initiated small trades & 19.26 & 5 & 78.52 & $-2,545$ & 1,560 \\
$\Delta$ (buy-sell) initiated large trades & 18.92 & 3 & 55.78 & -543 & 1,059 \\
\hline Dollar value of (buy-sell) small trades & 161,318 & 40,428 & 670,243 & $-17,100,000$ & $11,800,000$ \\
Dollar value of (buy-sell) large trades & $4,775,637$ & 369,841 & $33,900,000$ & $-1,400,000,000$ & $1,520,000,000$ \\
\hline Normalized imbalance of small trades & 0.1087 & 0.1265 & 1.6348 & -15.8431 & 7.1467 \\
Normalized imbalance of large trades & -0.0063 & 0.0141 & 1.4083 & -9.4254 & 7.1931 \\
\hline$N$ & 86,962 & & & & \\
\hline
\end{tabular}




\section{TABLE IV. Trade Reaction: Regression Results}

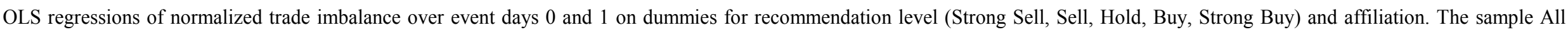

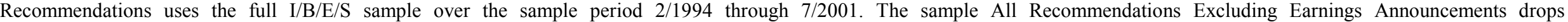

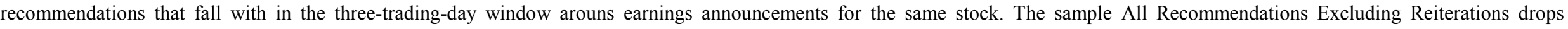

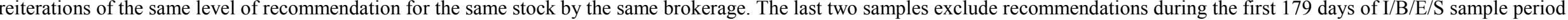

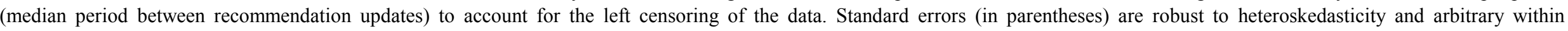
recommendation-date correlation across firms.

\begin{tabular}{|c|c|c|c|c|c|c|c|c|c|c|c|c|}
\hline & \multicolumn{3}{|c|}{ All Recommendations } & \multicolumn{3}{|c|}{$\begin{array}{l}\text { All Recommendations Excluding } \\
\text { Days of Earnings Announcements }\end{array}$} & \multicolumn{3}{|c|}{$\begin{array}{l}\text { All Recommendations Excluding } \\
\text { Reiterations }\end{array}$} & \multicolumn{3}{|c|}{$\begin{array}{l}\text { All Recommendations Excluding } \\
\text { Days of Earnings Announcements } \\
\text { and Excluding Reiterations }\end{array}$} \\
\hline & Large & Small & $\overline{\text { Difference }}$ & Large & Small & Difference & Large & Small & $\overline{\text { Difference }}$ & Large & Small & Difference \\
\hline & Trade & Trade & S-L & Trade & Trade & S-L & Trade & Trade & S-L & Trade & Trade & S-L \\
\hline \multirow[t]{2}{*}{ Strong Sell } & -0.103 & -0.105 & -0.002 & -0.088 & -0.105 & -0.018 & -0.105 & -0.099 & 0.006 & -0.086 & -0.102 & -0.017 \\
\hline & $(0.040)$ & $(0.050)$ & $(0.064)$ & $(0.043)$ & $(0.053)$ & $(0.068)$ & $(0.042)$ & $(0.051)$ & $(0.066)$ & $(0.045)$ & $(0.055)$ & $(0.070)$ \\
\hline \multirow[t]{2}{*}{ Sell } & -0.118 & -0.139 & -0.021 & -0.106 & -0.162 & -0.056 & -0.125 & -0.141 & -0.017 & -0.108 & -0.159 & -0.051 \\
\hline & $(0.034)$ & $(0.046)$ & $(0.057)$ & $(0.037)$ & $(0.048)$ & $(0.060)$ & $(0.035)$ & $(0.047)$ & $(0.059)$ & $(0.038)$ & $(0.049)$ & $(0.062)$ \\
\hline \multirow[t]{2}{*}{ Hold } & -0.091 & 0.007 & 0.099 & -0.095 & -0.015 & 0.080 & -0.097 & 0.010 & 0.107 & -0.099 & -0.013 & 0.086 \\
\hline & $(0.011)$ & $(0.014)$ & $(0.018)$ & $(0.012)$ & $(0.014)$ & $(0.019)$ & $(0.011)$ & $(0.014)$ & $(0.018)$ & $(0.012)$ & $(0.015)$ & (0.019) \\
\hline \multirow[t]{2}{*}{ Buy } & 0.011 & 0.134 & 0.123 & 0.007 & 0.123 & 0.116 & 0.018 & 0.141 & 0.123 & 0.014 & 0.130 & 0.116 \\
\hline & $(0.012)$ & $(0.013)$ & $(0.017)$ & $(0.012)$ & $(0.014)$ & $(0.018)$ & $(0.012)$ & $(0.014)$ & $(0.018)$ & $(0.013)$ & $(0.014)$ & $(0.019)$ \\
\hline \multirow[t]{2}{*}{ Strong Buy } & 0.112 & 0.243 & 0.131 & 0.106 & 0.230 & 0.124 & 0.124 & 0.251 & 0.127 & 0.118 & 0.241 & 0.123 \\
\hline & $(0.013)$ & $(0.014)$ & $(0.019)$ & $(0.013)$ & $(0.014)$ & $(0.020)$ & $(0.013)$ & $(0.014)$ & $(0.019)$ & $(0.013)$ & $(0.014)$ & $(0.020)$ \\
\hline \multirow[t]{2}{*}{ (Strong Sell)*Affiliation } & -0.196 & -0.838 & -0.643 & -0.213 & -1.004 & -0.791 & -0.142 & -0.850 & -0.709 & -0.215 & -1.007 & -0.792 \\
\hline & $(0.255)$ & $(0.331)$ & $(0.418)$ & $(0.274)$ & $(0.348)$ & $(0.443)$ & $(0.261)$ & $(0.344)$ & $(0.431)$ & $(0.274)$ & $(0.348)$ & $(0.443)$ \\
\hline \multirow[t]{2}{*}{ (Sell)*Affiliation } & 0.094 & -0.087 & -0.180 & 0.152 & -0.121 & -0.273 & 0.138 & -0.126 & -0.264 & 0.198 & -0.172 & -0.370 \\
\hline & $(0.254)$ & $(0.272)$ & $(0.372)$ & $(0.271)$ & $(0.284)$ & $(0.393)$ & $(0.259)$ & $(0.277)$ & $(0.379)$ & $(0.278)$ & $(0.289)$ & $(0.401)$ \\
\hline \multirow[t]{2}{*}{ (Hold)*Affiliation } & -0.001 & 0.005 & 0.006 & 0.004 & 0.001 & -0.004 & 0.002 & 0.000 & -0.002 & 0.007 & -0.005 & -0.012 \\
\hline & $(0.044)$ & $(0.056)$ & $(0.072)$ & $(0.049)$ & $(0.060)$ & $(0.077)$ & $(0.045)$ & $(0.058)$ & $(0.073)$ & $(0.049)$ & $(0.063)$ & $(0.080)$ \\
\hline \multirow[t]{2}{*}{ (Buy)*Affiliation } & -0.068 & 0.013 & 0.081 & -0.081 & 0.015 & 0.096 & -0.077 & 0.004 & 0.081 & -0.087 & 0.008 & 0.095 \\
\hline & $(0.034)$ & $(0.039)$ & $(0.052)$ & $(0.037)$ & $(0.043)$ & $(0.057)$ & $(0.035)$ & $(0.041)$ & $(0.054)$ & $(0.038)$ & $(0.044)$ & $(0.058)$ \\
\hline \multirow[t]{2}{*}{ (Strong Buy)*Affiliation } & -0.129 & -0.023 & 0.106 & -0.126 & -0.004 & 0.122 & -0.137 & -0.008 & 0.129 & -0.138 & 0.013 & 0.151 \\
\hline & $(0.036)$ & $(0.041)$ & $(0.055)$ & $(0.038)$ & $(0.044)$ & $(0.058)$ & $(0.037)$ & $(0.044)$ & $(0.057)$ & $(0.039)$ & $(0.046)$ & $(0.061)$ \\
\hline Sample size & 86,961 & 86,961 & & 76,457 & 76,457 & & 79,831 & 79,831 & & 70,138 & 70,138 & \\
\hline $\mathrm{R}^{2}$ & 0.0034 & 0.0085 & & 0.0032 & 0.0077 & & 0.004 & 0.0091 & & 0.0038 & 0.0085 & \\
\hline
\end{tabular}


Table IV. Trade Reaction: Regression Results (continued)

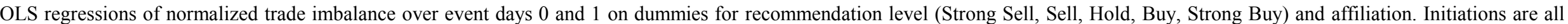

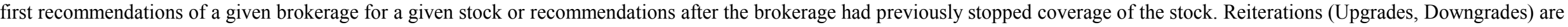

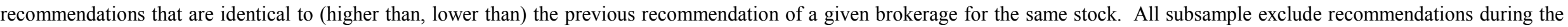

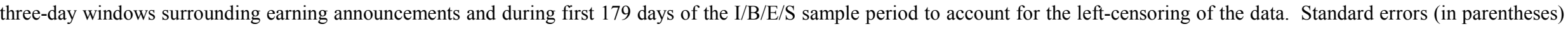
are robust to heteroskedasticity and arbitrary within recommendation-date correlation across firms.

\begin{tabular}{|c|c|c|c|c|c|c|c|c|c|c|c|c|}
\hline & \multicolumn{3}{|c|}{ Initiations } & \multicolumn{3}{|c|}{ Reiterations } & \multicolumn{3}{|c|}{ Upgrades } & \multicolumn{3}{|c|}{ Downgrades } \\
\hline & Large & Small & Difference & Large & Small & Difference & Large & Small & Difference & Large & Small & Difference \\
\hline & Trade & Trade & S-L & Trade & Trade & S-L & Trade & Trade & S-L & Trade & Trade & S-L \\
\hline \multirow[t]{2}{*}{ Strong Sell } & 0.012 & 0.174 & 0.162 & -0.194 & -0.325 & -0.132 & & & & -0.119 & -0.195 & -0.076 \\
\hline & $(0.098)$ & $(0.109)$ & $(0.146)$ & $(0.273)$ & $(0.425)$ & $(0.505)$ & & & & $(0.050)$ & $(0.062)$ & $(0.079)$ \\
\hline \multirow[t]{2}{*}{ Sell } & -0.105 & -0.126 & -0.021 & 0.043 & -0.393 & -0.436 & -0.302 & -0.301 & 0.001 & -0.100 & -0.163 & -0.063 \\
\hline & $(0.074)$ & $(0.107)$ & $(0.129)$ & $(0.213)$ & $(0.332)$ & $(0.395)$ & $(0.175)$ & $(0.238)$ & $(0.295)$ & $(0.044)$ & $(0.055)$ & $(0.070)$ \\
\hline \multirow[t]{2}{*}{ Hold } & -0.033 & -0.015 & 0.019 & 0.020 & 0.005 & -0.015 & -0.014 & 0.056 & 0.070 & -0.162 & -0.019 & 0.143 \\
\hline & $(0.017)$ & $(0.021)$ & $(0.027)$ & $(0.057)$ & $(0.060)$ & $(0.082)$ & $(0.042)$ & $(0.049)$ & $(0.064)$ & $(0.015)$ & $(0.019)$ & $(0.024)$ \\
\hline \multirow[t]{2}{*}{ Buy } & 0.028 & 0.136 & 0.107 & -0.037 & 0.111 & 0.148 & 0.080 & 0.194 & 0.114 & -0.101 & 0.035 & 0.137 \\
\hline & $(0.017)$ & $(0.020)$ & $(0.026)$ & $(0.041)$ & $(0.041)$ & $(0.058)$ & $(0.019)$ & $(0.022)$ & $(0.029)$ & $(0.023)$ & $(0.026)$ & $(0.035)$ \\
\hline \multirow[t]{2}{*}{ Strong Buy } & 0.095 & 0.221 & 0.126 & -0.044 & 0.161 & 0.205 & 0.140 & 0.260 & 0.120 & & & \\
\hline & $(0.018)$ & $(0.019)$ & $(0.026)$ & $(0.056)$ & $(0.062)$ & $(0.083)$ & $(0.018)$ & $(0.019)$ & $(0.026)$ & & & \\
\hline \multirow[t]{2}{*}{ (Strong Sell)*Affiliation } & -0.863 & -0.853 & 0.009 & & & & & & & -0.104 & -0.976 & -0.872 \\
\hline & $(0.855)$ & (1.144) & $(1.428)$ & & & & & & & $(0.284)$ & $(0.359)$ & $(0.458)$ \\
\hline \multirow[t]{2}{*}{$($ Sell)*Affiliation } & -1.919 & -3.220 & -1.302 & & & & & & & 0.266 & -0.060 & -0.326 \\
\hline & $(0.074)$ & $(0.107)$ & $(0.129)$ & & & & & & & $(0.277)$ & $(0.280)$ & $(0.394)$ \\
\hline \multirow[t]{2}{*}{ (Hold)*Affiliation } & 0.102 & 0.007 & -0.095 & -0.288 & -0.250 & 0.038 & -0.564 & 0.320 & 0.883 & 0.038 & -0.016 & -0.054 \\
\hline & $(0.098)$ & $(0.117)$ & $(0.153)$ & $(0.201)$ & $(0.296)$ & $(0.358)$ & $(0.254)$ & $(0.315)$ & $(0.404)$ & $(0.058)$ & $(0.074)$ & $(0.094)$ \\
\hline \multirow[t]{2}{*}{ (Buy)*Affiliation } & -0.124 & -0.085 & 0.039 & 0.033 & -0.041 & -0.074 & -0.099 & 0.265 & 0.363 & 0.045 & 0.118 & 0.074 \\
\hline & $(0.051)$ & $(0.059)$ & $(0.078)$ & $(0.217)$ & $(0.215)$ & $(0.305)$ & $(0.102)$ & $(0.103)$ & $(0.145)$ & $(0.067)$ & $(0.085)$ & $(0.109)$ \\
\hline \multirow[t]{2}{*}{ (Strong Buy)*Affiliation } & -0.200 & -0.106 & 0.095 & -0.040 & -0.310 & -0.271 & -0.030 & 0.204 & 0.235 & & & \\
\hline & $(0.051)$ & $(0.060)$ & $(0.079)$ & $(0.148)$ & $(0.165)$ & $(0.222)$ & $(0.059)$ & $(0.071)$ & $(0.092)$ & & & \\
\hline Sample size & 31,611 & 31,611 & & 3,979 & 3,979 & & 17,780 & 17,780 & & 20,747 & 20,747 & \\
\hline $\mathrm{R}^{2}$ & 0.0019 & 0.0081 & & 0.001 & 0.0052 & & 0.0068 & 0.0215 & & 0.0102 & 0.0019 & \\
\hline
\end{tabular}


FIGURE 1. Investor trade reactions to analyst recommendations.

The Figure displays the abnormal trade reaction to analyst recommendations if investors adjust downwards (Column 1) and if they do not adjust (Column 2).

\begin{tabular}{|c|l|l|l|}
\hline & Recommendations & Downward Adjustment & \multicolumn{1}{c|}{ No Adjustment } \\
\hline \multirow{4}{*}{ Unaffiliated } & strong sell & sell* & (strong) sell* \\
Analysts & sell & sell* & sell \\
& zero & $\downarrow$ sell & zero \\
& buy & $\downarrow$ weak buy or zero & buy \\
& strong buy & $\downarrow$ (less strong) buy & strong buy \\
\hline & strong sell & sell* & (strong) sell* \\
Affiliated & sell & sell* & sell \\
Analysts & zero & $\downarrow$ sell & zero \\
& buy & $\downarrow$ weak buy or zero & buy \\
& strong buy & $\downarrow$ (less strong) buy or zero & strong buy \\
\hline
\end{tabular}

* Alternatively, investors may display no abnormal trade reaction since previous negative (sell or hold) recommendations induced them to sell earlier. Short-sell constraints may strengthen this effect. 


\section{TABLE V. Robustness.}

\section{Panel A. Clustering}

OLS regressions of normalized trade imbalance. Trade reaction is summed over event days 0 and 1 . The recommendation levels (Strong Sell, Sell, Hold, Buy, Strong Buy) and Affiliation are dummy variables. Cluster by Year and Cluster by Brokerage Firm indicate that the standard errors are robust to heteroskedasticity and arbitrary within-year or, respectively, to arbitrary within-firm correlation. Sample period is 2/1994 through 7/2001. Standard errors in parentheses.

\begin{tabular}{|c|c|c|c|c|c|c|}
\hline & \multirow{2}{*}{\multicolumn{3}{|c|}{ Cluster by Year }} & \multirow{2}{*}{\multicolumn{3}{|c|}{ Cluster by Brokerage Firm }} \\
\hline & & & & & & \\
\hline & Large & Small & Difference & Large & Small & Difference \\
\hline & Trade & Trade & S-L & Trade & Trade & S-L \\
\hline \multirow[t]{2}{*}{ Strong Sell } & -0.103 & -0.105 & -0.002 & -0.103 & -0.105 & -0.002 \\
\hline & $(0.044)$ & $(0.032)$ & $(0.042)$ & $(0.031)$ & $(0.056)$ & $(0.049)$ \\
\hline \multirow[t]{2}{*}{ Sell } & -0.118 & -0.139 & -0.021 & -0.118 & -0.139 & -0.021 \\
\hline & $(0.031)$ & $(0.050)$ & $(0.044)$ & $(0.030)$ & $(0.057)$ & $(0.057)$ \\
\hline \multirow[t]{2}{*}{ Hold } & -0.091 & 0.007 & 0.098 & -0.091 & 0.007 & 0.098 \\
\hline & $(0.013)$ & $(0.021)$ & $(0.017)$ & $(0.009)$ & $(0.018)$ & $(0.019)$ \\
\hline \multirow[t]{2}{*}{ Buy } & 0.011 & 0.134 & 0.123 & 0.011 & 0.134 & 0.123 \\
\hline & $(0.015)$ & $(0.019)$ & $(0.014)$ & $(0.011)$ & $(0.010)$ & $(0.011)$ \\
\hline \multirow[t]{2}{*}{ Strong Buy } & 0.112 & 0.243 & 0.131 & 0.112 & 0.243 & 0.131 \\
\hline & $(0.018)$ & $(0.030)$ & $(0.016)$ & $(0.012)$ & $(0.023)$ & $(0.019)$ \\
\hline \multirow[t]{2}{*}{ (Strong Sell)*Affiliation } & -0.195 & -0.838 & -0.642 & -0.195 & -0.838 & -0.642 \\
\hline & $(0.216)$ & $(0.320)$ & $(0.463)$ & $(0.226)$ & $(0.266)$ & $(0.333)$ \\
\hline \multirow[t]{2}{*}{ (Sell)*Affiliation } & 0.094 & -0.087 & -0.180 & 0.094 & -0.087 & -0.180 \\
\hline & $(0.136)$ & $(0.184)$ & $(0.282)$ & $(0.233)$ & $(0.275)$ & $(0.339)$ \\
\hline \multirow[t]{2}{*}{ (Hold)*Affiliation } & -0.001 & 0.005 & 0.006 & -0.001 & 0.005 & 0.006 \\
\hline & $(0.038)$ & $(0.050)$ & $(0.066)$ & $(0.040)$ & $(0.077)$ & $(0.076)$ \\
\hline \multirow[t]{2}{*}{ (Buy)*Affiliation } & -0.068 & 0.013 & 0.081 & -0.068 & 0.013 & 0.081 \\
\hline & $(0.061)$ & $(0.054)$ & $(0.088)$ & $(0.040)$ & $(0.029)$ & $(0.042)$ \\
\hline \multirow[t]{2}{*}{ (Strong Buy)*Affiliation } & -0.129 & -0.023 & 0.106 & -0.129 & -0.023 & 0.106 \\
\hline & $(0.031)$ & $(0.032)$ & $(0.049)$ & $(0.036)$ & $(0.048)$ & $(0.047)$ \\
\hline Samp & 86,962 & 86,962 & & 86,962 & 86,962 & \\
\hline $\mathrm{R}^{2}$ & 0.0034 & 0.0085 & & 0.0034 & 0.0085 & \\
\hline
\end{tabular}

Panel B. Alternative Trade Size Groups

OLS regressions of normalized trade imbalance. Trade reaction is summed over event days 0 and 1. The recommendation levels (Strong Sell, Sell, Hold, Buy, Strong Buy) and Affiliation are dummy variables. Sample period is 2/1994 through 7/2001. Standard errors (in parentheses) are robust to heteroskedasticity and arbitrary within recommendation-date correlation across firms.

Trade Size - Dollar Value (thousands)

\begin{tabular}{rrrr}
\multicolumn{1}{c}{$\leq 5$} & \multicolumn{1}{c}{$5-10$} & $10-20$ & $20-50$ \\
\hline 0.014 & -0.125 & -0.112 & -0.018 \\
$(0.046)$ & $(0.044)$ & $(0.044)$ & $(0.045)$ \\
-0.001 & -0.095 & -0.145 & -0.012 \\
$(0.040)$ & $(0.040)$ & $(0.041)$ & $(0.037)$ \\
0.065 & 0.006 & -0.009 & 0.008 \\
$(0.012)$ & $(0.012)$ & $(0.012)$ & $(0.011)$ \\
0.129 & 0.107 & 0.070 & 0.057 \\
$(0.011)$ & $(0.011)$ & $(0.011)$ & $(0.011)$ \\
0.182 & 0.198 & 0.145 & 0.101 \\
$(0.012)$ & $(0.012)$ & $(0.012)$ & $(0.012)$ \\
-0.695 & -0.465 & -0.755 & -0.199 \\
$(0.288)$ & $(0.240)$ & $(0.331)$ & $(0.256)$ \\
-0.105 & -0.248 & 0.033 & -0.360 \\
$(0.269)$ & $(0.204)$ & $(0.238)$ & $(0.261)$ \\
0.088 & -0.089 & 0.003 & 0.057 \\
$(0.054)$ & $(0.050)$ & $(0.048)$ & $(0.046)$ \\
0.013 & 0.008 & 0.008 & -0.080 \\
$(0.038)$ & $(0.037)$ & $(0.036)$ & $(0.035)$ \\
0.059 & -0.041 & -0.029 & -0.080 \\
$(0.041)$ & $(0.040)$ & $(0.037)$ & $(0.038)$ \\
\hline 86,963 & 86,963 & 86,963 & 86,963 \\
0.0073 & 0.0062 & 0.0035 & 0.0017
\end{tabular}




\section{TABLE VI. Analyst Quality}

OLS regressions of normalized trade imbalance. Trade reaction is summed over event days 0 and 1 . The recommendation levels (Strong Sell, Sell, Hold, Buy, Strong Buy) and Affiliation are dummy variables. The Ever-Affiliated Brokerage sample includes only recommendations made by brokerages who issue at least one affiliated and one unaffiliated recommendation. The All-Star Analysts sample is limited to recommendations made by analysts who were listed in Institutional Investor Magazine's most recent October list of top analysts. Sample period is 2/1994 through 7/2001. Standard errors (in parentheses) are robust to heteroskedasticity and arbitrary within recommendation-date correlation across firms.

\begin{tabular}{|c|c|c|c|c|c|c|}
\hline & \multicolumn{3}{|c|}{ Ever-Affiliated Brokerages } & \multicolumn{3}{|c|}{ All-Star Analysts } \\
\hline & Large & Small & Difference & Large & Small & Difference \\
\hline & Trade & Trade & S-L & Trade & Trade & S-L \\
\hline \multirow[t]{2}{*}{ Strong Sell } & -0.129 & -0.144 & -0.015 & -0.153 & -0.152 & 0.001 \\
\hline & $(0.049)$ & $(0.068)$ & $(0.084)$ & $(0.090)$ & $(0.116)$ & $(0.147)$ \\
\hline \multirow[t]{2}{*}{ Sell } & -0.153 & -0.200 & -0.047 & -0.260 & -0.153 & 0.107 \\
\hline & $(0.041)$ & $(0.056)$ & $(0.070)$ & $(0.106)$ & $(0.168)$ & $(0.199)$ \\
\hline \multirow[t]{2}{*}{ Hold } & -0.098 & -0.001 & 0.097 & -0.120 & -0.010 & 0.110 \\
\hline & $(0.012)$ & $(0.015)$ & $(0.019)$ & $(0.024)$ & $(0.029)$ & $(0.038)$ \\
\hline \multirow[t]{2}{*}{ Buy } & 0.013 & 0.147 & 0.134 & 0.001 & 0.145 & 0.144 \\
\hline & $(0.012)$ & $(0.014)$ & $(0.019)$ & $(0.027)$ & $(0.029)$ & $(0.040)$ \\
\hline \multirow[t]{2}{*}{ Strong Buy } & 0.121 & 0.270 & 0.149 & 0.157 & 0.353 & 0.197 \\
\hline & $(0.014)$ & $(0.015)$ & $(0.020)$ & $(0.031)$ & $(0.035)$ & $(0.047)$ \\
\hline \multirow[t]{2}{*}{ (Strong Sell)*Affiliation } & -0.170 & -0.800 & -0.630 & -0.517 & -1.592 & -1.074 \\
\hline & $(0.257)$ & $(0.336)$ & $(0.423)$ & $(0.640)$ & $(0.679)$ & $(0.933)$ \\
\hline \multirow[t]{2}{*}{ (Sell)*Affiliation } & 0.128 & -0.026 & -0.155 & 0.713 & 0.510 & -0.203 \\
\hline & $(0.254)$ & $(0.274)$ & $(0.374)$ & $(0.505)$ & $(0.545)$ & $(0.743)$ \\
\hline \multirow[t]{2}{*}{ (Hold)*Affiliation } & 0.005 & 0.013 & 0.008 & 0.041 & 0.116 & 0.075 \\
\hline & $(0.045)$ & $(0.057)$ & $(0.072)$ & $(0.077)$ & $(0.105)$ & $(0.130)$ \\
\hline \multirow[t]{2}{*}{ (Buy)*Affiliation } & -0.070 & 0.001 & 0.071 & -0.056 & -0.051 & 0.005 \\
\hline & $(0.034)$ & $(0.039)$ & $(0.052)$ & (0.059) & $(0.070)$ & (0.092) \\
\hline \multirow[t]{2}{*}{ (Strong Buy)*Affiliation } & -0.138 & -0.050 & 0.088 & -0.150 & -0.156 & -0.006 \\
\hline & $(0.036)$ & $(0.042)$ & $(0.055)$ & $(0.067)$ & $(0.086)$ & $(0.109)$ \\
\hline Sample size & 68,948 & 68,948 & & 11,882 & 11,882 & \\
\hline $\mathrm{R}^{2}$ & 0.004 & 0.0104 & & 0.006 & 0.0135 & \\
\hline
\end{tabular}




\section{TABLE VII. Return Analysis}

\section{Panel A. Event-time Trading and Post-event Returns}

Regressions of market-adjusted abnormal buy-and-hold returns in percent (over the period of trading days indicated in parentheses in the first column) on the dollar value of net buy- minus sellinitiated trades (in \$m). Abnormal returns are calculated using a value-weighted market index. The sample is limited to all firms with at least one year of returns following the recommendation. The recommendation sample period is $2 / 1994$ through $7 / 2001$. Standard errors in parentheses.

\begin{tabular}{cccccc}
\hline & $\begin{array}{c}\text { Small } \\
\text { Trades } \\
\text { (in \$m) }\end{array}$ & $\begin{array}{c}\text { Large } \\
\text { Trades } \\
\text { (in \$m) }\end{array}$ & Constant & Sample size & \multirow{2}{*}{$\mathrm{R}^{2}$} \\
\hline \multirow{2}{*}{3 months $(2,64)$} & -0.1564 & 0.0046 & 0.1423 & 85,577 & 0.0001 \\
& $(0.1034)$ & $(0.0020)$ & $(0.0719)$ & & \\
\multirow{2}{*}{6 months $(2,128)$} & -0.4197 & 0.0085 & -0.0337 & 85,577 & 0.0002 \\
& $(0.1546)$ & $(0.0031)$ & $(0.1076)$ & & \\
12 months $(2,255)$ & -0.4003 & 0.0148 & 0.7301 & 85,577 & 0.0001 \\
& $(0.2439)$ & $(0.0048)$ & $(0.1697)$ & & \\
\hline
\end{tabular}

\section{Panel B. Analyst Recommendations and Portfolio Returns}

Daily portfolio returns in percent. The Long Portfolios are formed by purchasing stocks after strong-buy and buy recommendations; the Short Portfolios are formed by selling after strong-sell and sell recommendations. Both types of portfolios are formed separately for unaffiliated and affiliated analyst recommendations and over holding periods of three, six, and twelve months. A position is held until the holding period expires, the corresponding analyst stops covering the stock, or the analyst issues a new recommendation other than a hold. Hold recommendations extend the current position of the stock by (up to) another holding period. All transactions take place at the end of the day of recommendation. MktMinRf, SMB, HML and UMD represent the market, size, book-to-market and momentum factors respectively. Turnover is the average daily turnover of the given portfolio. The transaction cost estimates are based on the daily turnover of a portfolio and a transaction cost multiplier based on commissions data and the bid-ask spread. The resulting round-trip cost is $1.669 \%$ of traded value. Net returns are the gross abnormal return (the intercept from the regression) less transaction costs. Standard errors in parentheses.

\begin{tabular}{|c|c|c|c|c|c|c|c|c|c|c|c|c|}
\hline & \multicolumn{6}{|c|}{ Returns to Buying the Long Portfolio } & \multicolumn{6}{|c|}{ Returns to Selling the Short Portfolio } \\
\hline & \multicolumn{2}{|c|}{3 months } & \multicolumn{2}{|c|}{6 months } & \multicolumn{2}{|c|}{1 year } & \multicolumn{2}{|c|}{3 months } & \multicolumn{2}{|c|}{6 months } & \multicolumn{2}{|c|}{1 year } \\
\hline & Unaffiliated & Affiliated & Unaffiliated & Affiliated & Unaffiliated & Affiliated & Unaffiliated & Affiliated & Unaffiliated & Affiliated & Unaffiliated & Affiliated \\
\hline \multirow[t]{2}{*}{ MktMinRf } & 0.9469 & 1.1698 & 0.9515 & 1.1716 & 0.9494 & 1.1587 & -0.8626 & -1.1012 & -0.8858 & -1.0557 & -0.9214 & -1.0926 \\
\hline & $(0.0109)$ & $(0.0381)$ & $(0.0107)$ & $(0.0295)$ & $(0.0107)$ & $(0.0236)$ & $(0.0237)$ & $(0.1262)$ & $(0.0181)$ & $(0.1138)$ & $(0.0147)$ & $(0.1107)$ \\
\hline \multirow[t]{2}{*}{ SMB } & -0.3005 & 0.4326 & -0.3002 & 0.3712 & -0.3043 & 0.2877 & 0.3404 & -0.8464 & 0.3052 & -0.7711 & 0.3030 & -0.7838 \\
\hline & $(0.0123)$ & $(0.0431)$ & $(0.0121)$ & $(0.0333)$ & $(0.0121)$ & $(0.0267)$ & $(0.0268)$ & $(0.1403)$ & $(0.0205)$ & $(0.1283)$ & $(0.0166)$ & $(0.1250)$ \\
\hline \multirow[t]{2}{*}{ HML } & 0.1271 & 0.1611 & 0.1439 & 0.1448 & 0.1611 & 0.2146 & -0.2203 & -0.0716 & -0.2539 & -0.1248 & -0.2292 & -0.1678 \\
\hline & $(0.0164)$ & $(0.0573)$ & $(0.0161)$ & $(0.0443)$ & $(0.0161)$ & $(0.0355)$ & $(0.0357)$ & (0.1939) & $(0.0272)$ & $(0.1721)$ & $(0.0221)$ & $(0.1670)$ \\
\hline \multirow[t]{2}{*}{ UMD } & -0.0304 & -0.1243 & -0.0261 & -0.0809 & -0.0017 & -0.0682 & 0.0864 & 0.6151 & 0.0629 & 0.4618 & 0.0488 & 0.4081 \\
\hline & (0.0079) & $(0.0277)$ & $(0.0078)$ & $(0.0214)$ & $(0.0078)$ & $(0.0172)$ & $(0.0173)$ & $(0.0984)$ & $(0.0132)$ & $(0.0827)$ & $(0.0107)$ & $(0.0804)$ \\
\hline \multirow[t]{2}{*}{ Constant } & 0.0117 & 0.0027 & 0.0094 & -0.0105 & 0.0096 & -0.0059 & -0.0151 & -0.0348 & -0.0128 & -0.0588 & -0.0097 & -0.0572 \\
\hline & $(0.0063)$ & $(0.0218)$ & $(0.0061)$ & $(0.0169)$ & $(0.0061)$ & $(0.0135)$ & $(0.0136)$ & $(0.0714)$ & $(0.0104)$ & $(0.0650)$ & $(0.0084)$ & $(0.0634)$ \\
\hline Observations & 1891 & 1890 & 1891 & 1890 & 1891 & 1890 & 1891 & 1690 & 1891 & 1867 & 1891 & 1879 \\
\hline R-squared & 0.93 & 0.58 & 0.93 & 0.7 & 0.93 & 0.77 & 0.68 & 0.12 & 0.79 & 0.12 & 0.86 & 0.13 \\
\hline Gross Return & 0.0117 & 0.0027 & 0.0094 & -0.0105 & 0.0096 & -0.0059 & -0.0151 & -0.0348 & -0.0128 & -0.0588 & -0.0097 & -0.0572 \\
\hline Turnover & 0.0193 & 0.0270 & 0.0105 & 0.0141 & 0.0064 & 0.0085 & 0.0262 & 0.0247 & 0.0146 & 0.0162 & 0.0096 & 0.0119 \\
\hline Transaction Cost & 0.0322 & 0.0450 & 0.0175 & 0.0236 & 0.0107 & 0.0142 & 0.0438 & 0.0412 & 0.0244 & 0.0270 & 0.0161 & 0.0198 \\
\hline Net Return & -0.0205 & -0.0423 & -0.0081 & -0.0341 & -0.0011 & -0.0201 & -0.0589 & -0.0760 & -0.0372 & -0.0858 & -0.0258 & -0.0770 \\
\hline
\end{tabular}


